\title{
Los presbiterianos en Colombia (1856-1993): Una mirada histórica a través de su culto, liturgia y templos
} The Presbyterians in Colombia (1856-1993): A Historical Look through their Worship, Liturgy and Temples

\section{Os presbiterianos na Colômbia (1856-1993): uma visão histórica através de sua culto, liturgia e templos}

\section{Luis Eduardo Ramírez Suárez*}

\begin{abstract}
Resumen: El presente artículo explora, a través de una mirada histórica del culto, la liturgia y los templos, cómo la Iglesia Presbiteriana, desde su establecimiento a mediados del siglo XIX hasta su consolidación en el siglo XX, se instauró y contextualizó en Colombia, afrontando las luchas simbólicas en un ambiente de confrontación y diferenciación, en primer lugar, con la Iglesia Católica y, luego, con los movimientos teológicos al interior del mundo protestante. Esta exploración se da mediante una investigación bibliográfica y documental y un análisis del desarrollo del culto, la liturgia y los templos, lo cual permite vislumbrar los cambios y permanencias en los imaginarios, representaciones y prácticas que se materializaron en sus instituciones y discursos, y que impactaron todas las esferas de su realidad, cambios que fueron producto de la labor hermenéutica de leer la Biblia para hacerla relevante a su contexto.
\end{abstract}

Palabras claves: protestantismo; culto; templo; Iglesia Presbiteriana; liturgia; teología reformada.

* Colombiano. Magister en Teología del Seminario Bíblico de Colombia y doctorandus en Historia de la Universidad Nacional de Colombia, Sede Medellín. Rector de la Fundación Universitaria Seminario Bíblico de Colombia, Medellín, Colombia. Correo electrónico: rectoria@unisbc.edu.co. ORCID: https://orcid.org/0000-0001-5187-9412. 


\begin{abstract}
This article explores, through a historical view of worship, liturgy, and temples, how the Presbyterian Church was established and contextualized to Colombia, facing symbolic struggles in an environment of confrontation and differentiation, first with the Catholic Church and then with the theological movements within the Protestant world, from its establishment in the mid-19th century to its consolidation in the 20th century. This exploration takes place through bibliographic and documentary research, and an analysis of the development of worship, liturgy and temples, allowing us to glimpse the changes and permanence in the imaginaries, representations and practices that materialized in the church's institutions and discourses, and that impacted all the spheres of its reality. These changes were the product of the hermeneutical work of reading the Bible to make it relevant to its context.
\end{abstract}

Keywords: Protestantism; worship; temple; Presbyterian Church; liturgy; reformed theology.

Resumo: Este artigo explora, por meio de uma visão histórica do culto, da liturgia e dos templos, como a Igreja Presbiteriana foi estabelecida e contextualizada na Colômbia, enfrentando lutas simbólicas em um ambiente de confronto e diferenciação em primeiro lugar com a Igreja Católica, e depois com os movimentos teológicos dentro do mundo protestante, desde seu estabelecimento em meados do século XIX até sua consolidação no século XX. Essa exploração se dá por meio de pesquisa bibliográfica e documental e de uma análise do desenvolvimento do culto, da liturgia e dos templos, permitindo vislumbrar as mudanças e permanências nos imaginários, representações e práticas que se materializaram em suas instituições e discursos, e que impactaram todas as esferas de sua realidade, mudanças que foram produto do trabalho hermenêutico de ler a Bíblia para torná-la relevante para o seu contexto.

Palavras chaves: protestantismo; culto; templo, Igreja Presbiteriana; liturgia; teologia reformada. 


\section{Introducción ${ }^{1}$}

a Iglesia Presbiteriana fue la primera Iglesia Protestante ${ }^{2}$ que se estable-
ció en la Colombia continental con la llegada del misionero H. B. Pratt
en $1856 .{ }^{3}$ El peregrinar de la Iglesia Presbiteriana en el país ha estado marcado por penurias, persecuciones y confrontaciones con la Iglesia Católica. ${ }^{4}$ Pasó, junto con las demás iglesias protestantes, de ser tildada de «secta», ${ }^{5}$ por el catolicismo de corte tridentino, a ser considerada comunidad de «hermanos separados» por el catolicismo posconciliar del Vaticano II. ${ }^{6}$ A nivel político, el Estado colombiano solo consagró la libertad de conciencia y de cultos en la Constitución de 1991, que dio reconocimiento a las iglesias protestantes. ${ }^{7} \mathrm{~Pa}-$ radójicamente, fue en 1993, en pleno fervor de la apertura religiosa, cuando la Iglesia Presbiteriana enfrentó una división interna en dos sínodos. ${ }^{8}$

1 Este trabajo forma parte de mi tesis doctoral en historia en la Universidad Nacional de Colombia, Sede Medellín, que lleva por título: «Una historia de la Iglesia Presbiteriana en Colombia, 1956-1993», dirigida por el Dr. Gabriel Cabrera Becerra y defendida en Medellín en septiembre de 2020.

2 En este artículo Iglesias Protestantes — en adelante, IP — se refiere a aquellas iglesias hijas de la Reforma Protestante del siglo XVI, conocidas como denominaciones. Estas denominaciones surgieron en el mundo protestante como una nueva forma de las iglesias agruparse y relacionarse con base en sus énfasis teológicos y sistemas de gobierno en medio de la diversidad religiosa producto de la Reforma — siglo XVI- y de las Guerras Religiosas - siglo XVII- Ernst Troeltsch, The Social Teaching of the Christian Churches, Vol. 1, Trad. Olive Wyon (Londres, UK: George Allen and Unwin Ltd., 1949), 331-334. Para el caso de Colombia por ser la Iglesia Presbiteriana la primera IP en establecerse en el país (1856), básicamente el término se refiere exclusivamente a ella en los primeros 50 años; sin embargo, el término IP se usa como sinónimo de Iglesia Evangélica; como lo explica Juan A. Mackay, Las iglesias latinoamericanas y el movimiento ecuménico (New York, EE. UU.: CCAL, 1963), 23: «Es profundamente significativo que los cristianos protestantes en el continente sur, prefieran llamarse ellos mismos "evangélicos" y no "protestantes". No es que no tengan conciencia de las implicaciones teológicas y del testimonio histórico del protestantismo, o que estén avergonzados de ser conocidos como protestantes. [...] Al adoptar, por lo tanto, el término genérico de "evangélicos" para describirse a sí mismos, estaban de hecho y sin ruido, proclamando que la devoción al Evangelio, que se centraba en Cristo y es el tema principal de la Biblia, es lo que hace personas verdaderamente cristianas por sobre fronteras denominacionales»».

3 Constitución de la Iglesia Presbiteriana de Colombia. Presentación Rev. Guidoberto Mahecha (Bogotá, Colombia: Buena Semilla, 1987), 1-27. Francisco Ordóñez, Historia del cristianismo evangélico en Colombia (Bogotá, Colombia: CLC, 1956), 37-55.

4 Ordóñez, 478-508.

5 Eduardo Ospina, Las sectas protestantes en Colombia: Breve reseña histórica (Bogotá, Colombia: Imprenta Nacional, 1953), 26.

6 Concilio Vaticano II, Unitatis Redintegratio, Decreto sobre el ecumenismo, 21 de noviembre de 1964.

7 República de Colombia, Constitución Politica de Colombia, 1991, Gaceta Constitucional n. ${ }^{\circ} 116$ de 20 de julio de 1991; Jorge Munévar, «La libertad religiosa en Colombia: orígenes y consecuencias», en: Historia del cristianismo en Colombia. Corrientes y diversidad, dir. Ana María Bidegain (Bogotá, Colombia: Taurus, 2004), 247-256.

8 Archivo Iglesia Presbiteriana de Colombia — en adelante, AIPC—, Convocatoria a la Iglesia Presbiteriana de Colombia a un Sínodo Extraordinario de Unidad en Ibagué los días, 13 al 15 de agosto de 1993; AIPC, Declaración Consejo Sínodo Iglesia Presbiteriana de Colombia, Barranquilla, 29 de julio de 1993, f. 1-2; AIPC, Acta Reunión Extraordinaria del Venerable Sínodo, Ibagué, 15 de agosto de 1993, f. 1-6; AIPC, Acta $n .^{\circ}$ 1, Reunión Sínodo Extraordinario Iglesia Presbiteriana de Colombia, agosto 13-15 de 1993, f. 1-7; AIPC, Acta Compromisoria, Ibagué, 15 de agosto de 1993, f. 1-3; Juana de Bucana, La Iglesia evangélica en Colombia: una historia (Bogotá, Colombia: WEC International, 1995), 103, 182, 183. 
Con el establecimiento de la Iglesia Presbiteriana se dio inicio en Colombia a la manifestación de una nueva expresión del cristianismo con su proyecto religioso, educativo, político y social. ${ }^{9}$ Los gobiernos liberales, con su política de apertura al comercio internacional, fueron propicios a la llegada de extranjeros y con ellos a la llegada de las nuevas ideas. ${ }^{10}$ Los gobiernos estaban interesados en un nuevo sistema educativo que ayudaran a implantar los ideales de progreso. ${ }^{11}$ En especial, el gobierno de José Hilario López (1849-1853) adelantó una agenda que incluía una educación liberal que no fuera administrada por la Iglesia Católica. ${ }^{12}$ Además, el pensamiento liberal promovió la libertad de imprenta, la libertad de enseñanza y la libertad de culto, entre otras, como fundamentos de la democracia. ${ }^{13}$ Esto último no implicaba que los liberales fueran «antirreligiosos» sino que anhelaban para la república una «religión de culto privado», ${ }^{14} \mathrm{y}$ una separación entre Iglesia y Estado con objetivos y fines diferentes, además de un sistema económico alternativo al colonial. ${ }^{15}$ Los presbiterianos jugaron un papel importante porque promovieron y participaron en el proyecto modernizador y los ideales de progreso de los liberales. ${ }^{16}$ En el siglo XX, en el contexto político de Colombia, la Iglesia Presbiteriana experimentó la influencia de los nuevos lineamientos pastorales fruto de los Congresos Misioneros Mundiales Protestantes: Edimburgo (1910) y Panamá (1916), donde se definieron las líneas del protestantismo latinoamericano, las cuales determinaron el trabajo de las iglesias tanto las que se identificaron con el movimiento ecuménico como las que se identificaron con el movimiento evangélico. ${ }^{17}$

9 Pablo Moreno, Por momentos hacia atrás... por momentos hacia adelante: una historia del protestantismo en Colombia 1825-1945 (Cali, Bonaventuriana: 2010), 63-64: «Con Pratt el protestantismo optó por una inserción definitiva en las condiciones favorables que las reformas liberales radicales de mediados del siglo habían adelantado. [...] con Pratt hubo también una ruptura en la forma de inserción del protestantismo en el sentido de que ahora había un interés explícito de aprovechar esas condicione sociales para establecer espacios de reunión pública y permanente, articulándose con el proyecto educativo de los radicales»; Gabriel Cabrera Becerra, Los poderes en la frontera. Misiones católicas y protestantes, y Estados en el Vaupés colombo-brasileño, 1923-1989 (Medellín, Colombia: Universidad Nacional de Colombia, 2015), 44-45; Javier Augusto Rodríguez, «Primeros intentos de establecimiento del protestantismo en Colombia», en: Historia del cristianismo en Colombia. Corrientes y diversidad, dir. Ana María Bidegain (Bogotá, Colombia: Taurus, 2004), 289; Abraham Kuyper, Lectures on Calvinism (Grand Rapids, EE. UU.: Eerdmans, 1976), 17.

10 José Manuel Groot, Historia eclesiástica y civil de la Nueva Granada, Tomo IV (Bogotá, Colombia: Biblioteca de autores colombianos, 1953), 308-309; Álvaro Tirado Mejía, El Estado y la política en el siglo $X I X, 4^{a}$ edición (Bogotá, Colombia: El Áncora Editores, 2001), 23-24.

11 Moreno, 36.

12 Tirado Mejía, 19-20, 26, 37.

13 Gerardo Molina, Las ideas liberales en Colombia 1849-1959, Tomo I, 5 a edición (Bogotá, Colombia: Universidad Libre, Cátedra Gerardo Molina, Corporación Gerardo Molina, 2006), 45-47.

14 Tirado Mejía, 71-72.

15 Molina, 43, 53-54.

16 Ricardo Arias, El episcopado colombiano: Intransigencia y laicidad, 1850-2000 (Bogotá: Uniandes, 2003), 18 .

17 Juan Fonseca Ariza, Misioneros y civilizadores: Protestantismo y modernidad en el Perú (1915-1930) (Lima, Perú: Fondo Editorial PUCP, 2002), 125; Mackay, Las Iglesias Latinoamericanas..., 11; Samuel 
En la medida en que el presbiterianismo avanzó en Colombia, causó choques de fuerzas que produjeron diferentes formas de resistencia y radicalización. ${ }^{18}$ Desde su establecimiento, esta nueva expresión de fe comenzó un proceso de adaptación y consolidación; fundamentada en su propia herencia, estructuró y contextualizó su mensaje y praxis. En este proceso de establecimiento y contextualización en el país, en un ambiente de confrontación y diferenciación, en primer lugar con la Iglesia Católica y, luego, con los movimientos teológicos al interior del mundo protestante, los presbiterianos colombianos experimentaron cambios en sus representaciones, imaginarios y prácticas que se materializan en sus instituciones y discursos, tal como se enmarca en la historia cultural. ${ }^{19}$ Los cambios en las comunidades de fe, muchas veces imperceptibles, fueron producto de la labor hermenéutica de leer la Biblia para hacerla relevante a su contexto. En este proceso de actualización se fueron produciendo y apropiando nuevas prácticas y representaciones que impactaron todas las esferas de la realidad. ${ }^{20}$ Un acercamiento a través de una mirada histórica de su culto, liturgia y templos podrá evidenciar las luchas simbólicas que afrontó la Iglesia Presbiteriana en Colombia, y descubrir el impacto de la reflexión teológica en la praxis cúltica de esta comunidad cristiana. ${ }^{21}$

\section{El culto}

El culto y la liturgia protestante están íntimamente relacionados con la lectura de las Escrituras, y esto, a su vez, tiene que ver con el principio del libre examen. Para la fe protestante y para el desarrollo de su culto y liturgia ha sido indispensable la Biblia. ${ }^{22}$ Por eso, desde el primer momento del establecimiento del presbiterianismo en Colombia se presentó la urgencia de tener la Biblia en

Escobar, «¿Qué significa ser evangélico hoy?», Misión, vol. 1, n. ${ }^{\circ} 1$ (marzo-junio, 1982): 15-39; Samuel Escobar, «Los movimientos de cooperación evangélica en América Latina», Misión, vol. 1, n. ${ }^{\circ} 1$ (marzo-junio, 1982): 103-114. José Míguez Bonino, «El rostro liberal del protestantismo», en: Unidad y diversidad del protestantismo latinoamericano. El testimonio evangélico hacia el tercer milenio: Palabra, espíritu y misión, CLADE IV, Bonino, José Míguez, Juan Sepúlveda y Rigoberto Gálvez (Buenos Aires, Argentina: Ediciones KAIROS, 2002), 13-14.

18 Pierre Bourdieu, «Génesis y estructura del campo religioso», Relaciones, vol. 27, n. 108 (2006): 63-64, https://www.colmich.edu.mx/relaciones25/files/revistas/108/pdf/PierreBourdieu.pdf; The Fifty-Ninth Annual Report of the Board of Foreign Missions of the Presbyterian Church of the United States of America, New York, Presbyterian Church the USA, 1896, 232-233.

19 Diana Luz Ceballos Gómez, ed., Prácticas, territorios y representaciones en Colombia 1849-1960 (Medellín, Colombia: Universidad Nacional de Colombia, 2009), 19-29.

20 Ceballos, prácticas, territorios y representaciones..., 20 y 23; Peter Burke, «Una historia cultural y social de los desechos», en Peter Burke. Debates y perspectivas de la nueva historia cultural, eds. Yobenj Aucardo Chicangana-Bayona y Liliana Cortés Garzón (Medellín, Colombia: Universidad Nacional de Colombia, 2011), 73-75.

21 Bourdieu, «Génesis y estructura...», 63-64; Ceballos, Prácticas, territorios y representaciones..., 23.

22 Alfonso López Michelsen, La estirpe calvinista de nuestras instituciones políticas (Bogotá, Colombia: Tercer Mundo, 1966), 30: «La principal característica del calvinismo es su adhesión textual a la Sagrada Escritura, y la eliminación de todos los elementos de otro origen, así sea la tradición o la filosofía. El mayor empeño que pone Calvino en sus obras es que estas sean lógicas y coherentes, más que ricas en ideas o en 
español. Cuando el Rev. Pratt, en su trabajo pastoral se dio cuenta de que el español de la Biblia de la antigua versión Reina Valera no correspondía al lenguaje contemporáneo del pueblo y dificultaba el entendimiento del mensaje del evangelio, mprendió la tarea de hacer una revisión del Nuevo Testamento conocida como versión moderna. ${ }^{23}$

Desde la llegada del Rev. Pratt a Bogotá en 1856, se dio inicio a la celebración de los servicios religiosos, el primero fue oficiado en inglés en el Hotel Dickson. Poco tiempo después, estos servicios se comenzaron a ofrecer en español, esta práctica causó gran malestar en el clero y los intelectuales católicos ${ }^{24} \mathrm{El}$ hecho de celebrar los cultos en español implicó que el interés no estaba en atender a los extranjeros residentes en Colombia, sino en hacer proselitismo entre los colombianos..$^{25}$ Sin embargo, el culto presbiteriano no tuvo la carga política que los liberales hubieran querido que presentara; por el contrario, su mensaje fue evangélico centrado en la salvación, lo cual desilusionó a muchos de los liberales. ${ }^{26}$ Cabe recordar que desde inicios de la República se expidieron leyes que permitieron a los extranjeros profesar su culto, como parte de las concesiones de los tratados comerciales con Inglaterra (1825) y los E.E.U.U. (1846); ${ }^{27}$ también los primeros gobiernos tuvieron el propósito de ser reconocidos por las potencias protestantes y permitir la libertad de culto fue una manera de demostrarles sus intenciones serias de amistad. ${ }^{28}$ La reforma constitucional de 1853 y la Constitución de 1863 consagraron en Colombia la libertad de culto, permitiendo la libertad de conciencia y la profesión pública o privada de cualquier religión, siempre que no interfiriera con la soberanía nacional o perturbara la paz pública. ${ }^{29}$ Este

experiencia. Por eso el calvinismo es la más protestante y antirromana de las iglesias reformadas»; Kuyper, Lectures on Calvinism, 56.

23 El Nuevo Testamento de nuestro señor y salvador Jesucristo, Versión Moderna (Nueva York, E.U.A.: Sociedad Bíblica Americana, 1894); Ordóñez, 45.

24 Ordóñez, 39; Molina, 111.

25 Rodríguez, «Primeros intentos...», 296.

26 Ordóñez, 39; Max Weber, La ética protestante y el espíritu del capitalismo, Trad. de Luis Legaz Lacambra (Barcelona, España: Península, 1999), 105-106.

27 En especial estas concesiones se establecieron en el Tratado de amistad, comercio y navegación entre Colombia e Inglaterra, Tratado de la República de la Nueva Granada e Inglaterra, Artículo 12º, Bogotá, 18 de abril de 1825 y el Tratado general de paz, amistad, navegación y comercio entre la República de la Nueva Granada y los Estados Unidos de América, Tratado Mallarino-Bidlack, Artículo 14º, Bogotá, 12 de diciembre de 1846.

28 Molina, 111; David Bushnell, El régimen de Santander en la Gran Colombia (Bogotá, Colombia: El Áncora, 1985), 177-185 y 224-236; Tirado Mejía, 23-24; Leslie Bethell (ed.), Historia de América Latina (Barcelona, España: Crítica, 1991), 209-233; Carlos Arboleda Mora, «El protestantismo en Colombia 1810-1920», en: El diálogo ecuménico y el pensamiento de Calvino en sus 500 años, comp. Carlos Arboleda Mora y Fernando Alexander Sanmiguel Martínez (Medellín, Colombia: Universidad Pontificia Bolivariana, 2015), 25.

29 República de Colombia, Constitución Politica de los Estados Unidos de Colombia (Bogotá, Colombia: Imprenta i Estereotipia de Medardo Rívas, 1871). 
clima de tolerancia religiosa y de libertad de culto y conciencia fue revertido con la Constitución de $1886^{30}$ y el Concordato de $1887 .{ }^{31}$

El domingo 24 de noviembre de 1861 fue una fecha especial en la historia de la Iglesia Presbiteriana en Colombia. En este día se celebró un culto donde se ofició, por primera vez, en suelo colombiano, el sacramento de la Cena del Señor, ${ }^{32}$ con contenido y forma protestante, lo cual implicó un desafío a la fe de la Iglesia Católica y a las disposiciones del Concilio de Trento. ${ }^{33}$

El culto protestante traído a Colombia por los presbiterianos rompía con la estructura y la forma de la misa tridentina de la Iglesia Católica. En cuanto al canon mismo de las Escrituras, el Concilio de Trento se abrogó la autoridad de determinar el canon tal como se hallaba en la Vulgata. ${ }^{34}$ El hecho de que los protestantes acudieran directamente a las Escrituras y rechazaran la autoridad que reclamaba la Iglesia para determinar cuáles eran las Escrituras y cómo interpretarlas, en el fondo reflejó un conflicto de autoridad. ${ }^{35}$ Para la fe reformada, ni la autoridad de las Escrituras ni su interpretación dependían de la Iglesia; las Escrituras mismas eran su propia intérprete y el medio indispensable para el conocimiento seguro de Dios. ${ }^{36}$ A su vez, el Concilio de Trento, con el fin de evitar la herejía, no permitió la interpretación privada de la Biblia y prohibió imprimir, tener o vender el texto sagrado sin la autorización de la Iglesia. ${ }^{37}$ En cambio para los protestantes regían los principios de la libre interpretación y perspicuidad de las Escrituras, doctrina que afirma que las Escrituras son tan claras que cualquier persona puede entender su mensaje por la iluminación del Espíritu Santo. ${ }^{38}$

30 República de Colombia, Constitución de la República de Colombia (Bogotá, Colombia: Imprenta de Vapor de Zalamea HS., 1886).

31 Ministerio del Interior, Colombia y la libertad de cultos, enero 5 de 2018; Concordato entre la Santa Sede y la República de Colombia (1887).

32 Ordóñez, 55-57; Javier Augusto Rodríguez Sanín. Hacia una historia del protestantismo en Colombia (Medellín, Colombia: UPB y Corporación Honorable Presbiterio Central de la Iglesia Presbiteriana de Colombia, 2019), 60.

33 El Concilio de Trento (1547-1563) se desarrolló bajo los papados de Paulo III, Julio III y Pío IV, y tuvo el fin de refutar las doctrinas protestantes y fortalecer la disciplina eclesiástica de la Iglesia Católica.

34 Documentos del Concilio de Trento, Sesión IV. Las Sagradas Escrituras (Celebrada el 8 de abril de 1546); Theo Donner, El Texto que interpreta al lector: una exposición de la Biblia (Medellín, Colombia: FUSBC, 2009), 126; La Vulgata es la traducción de la Biblia hebrea y griega hecha por san Jerónimo de Estridón al latín en el siglo IV.

35 Theo Donner, Una Introducción a la historia y teología de la Reforma (Medellín, Colombia: Seminario Bíblico de Colombia, 1987), 129; H. B. Pratt, La Biblia y sus opositores: escrito dedicado a los romanistas adversarios de la Biblia y al señor José Manuel Groot en particular por H. B. Pratt, ministro protestante en el Socorro (Bogotá, Colombia: Imprenta Gaitán, 1875); López, La estirpe calvinista ..., 62; E. Troeltsch, El Protestantismo y el mundo moderno, Trad. de Eugenio Ímaz (México - Buenos Aires, México-Argentina: FCE, 1951), 19.

36 Inst. IV, ix, 8; Inst. I, vii, 3; Inst. I, i, 2; Inst. I, ii, 1; Inst. I, x, 4; Luis Eduardo Ramírez, Aportes del principio reformado de la Sola Scriptura para la interpretación y enseñanza de la Biblia, Tesis de Maestría en Teología (Medellín, Colombia: SBC, 2001), 66-73.

37 Documentos del Concilio de Trento, Sesión IV. Las Sagradas Escrituras, http://www.conoze.com/doc. php?doc $=5242$.

38 R. C. Sproul, Escogido por Dios, Trad. de Demetrio Cánovas Moreno (Miami: Unilit, 1993), 11; Inst. I, ix, 4. 
Una diferencia importante entre el culto protestante y el católico tridentino fue que este último debía celebrase en latín, ${ }^{39}$ poniendo el énfasis en la persona que oficiaba y no en el feligrés, dando así más importancia al rito que a la enseñanza. ${ }^{40}$ Para el culto protestante la exposición de las Escrituras ocupó un lugar central en la liturgia, ${ }^{41}$ por lo tanto la meta del predicador era exponer fielmente las Escrituras. ${ }^{42}$

Por otro lado, la Iglesia Presbiteriana, como la mayoría de las Iglesias Protestantes, solo reconocía dos sacramentos: el bautismo y la Cena del Señor. ${ }^{43} \mathrm{La}$ excomunión se aplicó a quienes afirmaron la doctrina protestante que el sacramento tenía solo el fin de fomentar la fe y que la gracia se podía conseguir con la fe en las promesas de Dios sin la mediación sacramental; en otras palabras, que los sacramentos no eran indispensables para la salvación. ${ }^{44}$ Los presbiterianos también predicaron que la eficacia del sacramento estaba unida a la proclamación de la Palabra y que dicha eficacia no era ex opere operato. ${ }^{45}$

Otra divergencia teológica tenía que ver con el sacrifico de la misa católica, ceremonia de expiación para satisfacer a Dios por los pecados de los vivos y de los muertos, que afirmaba que en el sacramento se contenía y sacrificaba incruentamente a Cristo. ${ }^{46}$ El Sacramento de la Eucaristía para la Iglesia Católica se sustentó en la doctrina de la transustanciación, que creía que al momento de la consagración del pan y el vino, las sustancias de estos elementos se convertían en el cuerpo y la sangre real de Cristo ${ }^{47}$ En contraste, el culto presbiteriano era concebido como «una celebración de la resurrección de Cristo y una anticipación de la plenitud del reino venidero de Dios», ${ }^{48}$ allí Cristo no es ofrecido al Padre, ni se

39 Documentos del Concilio de Trento, Sesión XXII. El Sacrificio Eucarístico, la VI celebrada en tiempo del sumo Pontífice Pío IV en 17 de setiembre de 1562, http://www.conoze.com/doc.php?doc=5291.

40 Émile Durkheim, Las formas elementales de la vida religiosa, Trad. de Ramón Ramos (Madrid, España: Akal, 1982), 398; Troeltsch, El Protestantismo..., 47-48.

41 Donner, Una introducción..., 139 y 147.

42 Inst. IV, i, 5; The Twenty-Ninth Annual Report of the Board of Foreign Missions of the Presbyterian Church of the United States of America (New York, Presbyterian Church the USA, 1866), 11; lgunos hombres influyentes apreciaron la predicación en español porque creían que era una buena forma de contrarrestar las enseñanzas católicas y las supersticiones del pueblo.

43 George S. Hendry, La Confesión de Westminster para el día de hoy: una interpretación actual, Trad. de Jorge Lara-Braud (Bogotá: CEPAL, 1966), 232; Juan A. Mackay, El sentido presbiteriano de la vida: lo que significa vivir y adorar como presbiteriano, Trad. de Abel Clemente (Englewood, USA: Prentice Hall, S.f.), 220-223.

44 Documentos del Concilio de Trento, Sesión VII. Los Sacramentos (Celebrada en el día 3 de marzo de 1517); Donner, Una introducción ..., 157; Weber, 199.

45 Inst. IV, xiv, 3-5; La eficacia Ex opere operato se refiere a que el sacramento es eficaz automáticamente debido a una administración correcta, independiente de la fe, méritos y moral del oficiante o los destinatarios.

46 Documentos del Concilio de Trento, Sesión XXII. El Sacrificio Eucarístico, la VI celebrada en tiempo del sumo Pontífice Pío IV (17 de setiembre de 1562); Inst. IV, xviii, 1-7.

47 Documentos del Concilio de Trento, Sesión XIII. El Santísimo Sacramento de la Eucaristía (Celebrada en el día 3 de marzo de 1517 y 11 de octubre de 1551); Pratt, La Biblia y sus opositores, 38-39.

48 Constitución de la Iglesia Presbiteriana EEUUA, Libro de Orden, Versión oficial en español (Louisville: Oficina de la Asamblea General Iglesia Presbiteriana EEUUA, 2017), 67. 
hace ningún sacrificio de remisión de los pecados; es una ceremonia de conmemoración del sacrificio que se realizó una sola vez. ${ }^{49}$ Los anteriores asuntos de fe tuvieron implicaciones trascendentales, cualquier persona que no aceptara estas doctrinas estaba rompiendo definitiva e irreparablemente con la Iglesia Católica.

En el culto protestante, la Biblia tomó un lugar central en su liturgia, por lo tanto, esta debía ser leída, cantada, proclamada y escuchada. ${ }^{50}$ La música y el canto congregacional llegaron a ser elementos característicos de esta liturgia, por eso para la Iglesia Presbiteriana colombiana una de las necesidades apremiantes fue tener un himnario para sus cultos. ${ }^{51}$

El 1 de enero de 1865 fue la fecha que marcó el inicio propiamente dicho de la Iglesia Presbiteriana y, por ende, de la Iglesia Evangélica en el país. ${ }^{52}$ En este servicio religioso se recibieron los primeros colombianos convertidos a la fe presbiteriana como miembros de la congregación; estos creyentes habían hecho confesión pública de fe y renunciaron definitivamente al culto católico tanto en su doctrina como en su práctica. ${ }^{53}$

El cambio radical de estos primeros presbiterianos colombianos fue un cambio de convicciones y de creencias; como lo expresa Theo Donner, los cambios de convicciones y creencias son los más decisivos y radicales en el ser humano. ${ }^{54}$ El rompimiento con la Iglesia Católica y aceptación de este nuevo mensaje representó para los conversos la pena de excomunión; e implicó un cambio irreversible en cuestiones de fe..$^{55} \mathrm{El}$ culto de 1865 no indicó un acto de simple ceremonial religioso, fue evidencia de que en Colombia irrumpió un sentido diferente de ser cristiano. ${ }^{56}$ Para el cristiano el culto trasciende la

49 Hendry, La Confesión de Westminster..., 239-240; Inst. IV, xvii, 1-5; Donner, Una introducción..., 153-161.

50 Mackay, El sentido presbiteriano..., 207.

51 Rodríguez, Hacia una historia ..., 74; Ordóñez, 52.

52 Rodríguez, Hacia una historia ..., 66; Ordóñez, 57; El rito del bautismo o iniciación en la fe tiene implicaciones profundas en la autoidentificación social dentro de un grupo o sociedad.

53 Es aquí donde toman relevancia las palabras de José Ortega y Gasset, Historia como sistema (Madrid, España: ESPASA-CALPE, 1971), 10-12: «Antes que hacer algo, tiene cada hombre que decidir, por su cuenta y riesgo, lo que va a hacer. Pero esta decisión es imposible si el hombre no posee algunas convicciones sobre lo que son las cosas en su derredor, los otros hombres, él mismo. Sólo en vista de ellas puede preferir una acción a otra. Puede, en suma, vivir. De aquí que el hombre tenga que estar siempre en alguna creencia y que la estructura de su vida dependa primordialmente de las creencias en que esté y que los cambios más decisivos en la humanidad sean los cambios de creencias, la intensificación o debilitación de las creencias».

54 Theo Donner, Una nueva forma de pensar. Borradores para una cosmovisión cristiana (Medellín, Colombia: SBC, 1993), 8-10; Theo Donner, Posmodernidad y fe: una cosmovisión cristiana para un mundo fragmentado (Barcelona, Colombia: CLIE, 2012), 18-19. Donner cita a Ortega y Gasset y hace un análisis magistral de la misma.

55 Weber, 113-114, afirma que este cambio de fe se debe estudiar más allá de la aceptación nuevos dogmas; Kuyper, Lectures on Calvinism, 13-17. Los presbiterianos desarrollaron una teología reformada basada en los pilares Sola Fe, Sola Gracia y Sola Escritura; un sistema de gobierno de democracia representativa por ancianos y una forma de para desempeñarse en la vida política y social en las diversas esferas de la vida

56 Mackay,El sentido presbiteriano..., 27-28; Kuyper, Lectures on Calvinism, 13-17; Luis Eduardo Ramírez Suárez, «Una historia de la Iglesia Presbiteriana en Colombia, 1993-2013», Ventana Teológica, año 4, $5^{\text {a }}$ 
realidad material, es una fuerza que lo transforma y lo capacita para vivir de forma extraordinaria su fe como afirma Durkheim:

La experiencia nos enseña, en efecto, que cuando los hombres se reúnen, cuando viven una vida común, de esa misma agrupación brotan fuerzas excepcionalmente intensas que los dominan, los exaltan, que conducen su tono vital a un grado que no conocen en la esfera privada. Bajo el efecto del entusiasmo colectivo, son a veces asaltados por un verdadero delirio que los empuja a realizar actos en los que ellos mismos no se reconocen. ${ }^{57}$

A su vez, el establecimiento de la Iglesia Presbiteriana marcó una nueva manera en que el Estado se relacionaría con la Iglesia, ya que el protestantismo no se presentaba como una «entidad homogénea», sino que debía ser concebido como una unidad en propósito y una diversidad en la expresión de lo cristiano, reflejada en múltiples denominaciones ${ }^{58}$ pues de aquí en adelante cada Iglesia Protestante que se estableció en Colombia traía su propia identidad. Los presbiterianos no fueron la excepción, este sentido presbiteriano de ser cristianos implicó la producción y apropiación de representaciones, imaginarios y prácticas que se materializaron en sus instituciones y discursos. ${ }^{59}$

En la medida en que el presbiterianismo avanzó en Colombia causó un choque de fuerzas que recompuso la estructura social y que produjo diferentes formas de resistencia y radicalización. ${ }^{60}$ Desde su establecimiento, esta nueva expresión de la fe comenzó un proceso de consolidación, afianzada en su herencia teológica, estructuró y contextualizó su mensaje y definió su propia identidad. Como lo expresa Daniel Salinas, en América Latina, el protestantismo fue un proceso de construcción no solo de importación:

[...] El desarrollo del pensamiento evangélico en Latinoamérica muestra una simbiosis entre los elementos exógenos y endógenos que a lo largo de los años han interactuado para definir nuestra situación actual como protagonistas activos en el panorama religioso y social en nuestro continente. Nuestra historia muestra que desde un comienzo los evangélicos se preocuparon por definir, dentro de su contexto, la fe y la práctica religiosa pertinente. Si bien al comienzo hubo mucha repetición de

ed. (4 de diciembre de 2013): 22-23, http://www.unisbc.edu.co/files/VT05-Art03-Ramrez2013.pdf.

57 Émile Durkheim, «El porvenir de la religión (1914)», en Breve estudio de la representación del tiempo en la religión y en la magia, Hubert, Henri, Trad. Sonia Muñoz (Cali, Colombia: Archivos del Índice, 2006), 86.

58 Jaime Ortiz Hurtado, ¿Quiénes son los evangélicos? Creencias, posiciones y compromisos de los cristianos o evangélicos de la actualidad (Santafé de Bogotá, Colombia: Horizonte Impresores, 1995), 14-17; López, La estirpe calvinista..., 77.

59 Ceballos, Prácticas, territorios y representaciones..., 20-28; Kuyper, Lectures on Calvinism.

60 Bourdieu, «Génesis y estructura...», 63-64. 
lo importado, no fue un proceso lineal, sino que, más bien, las tradiciones recibidas se evaluaron y latinizaron para hacerlas nuestras. ${ }^{61}$

La intención en este artículo no es presentar una historia del culto presbiteriano en Colombia, sino mostrar cómo el canto reflejó aspectos de esta fe en la vivencia del culto en diferentes periodos de su historia y cómo adoptó diversos matices autóctonos de cada región. Durkheim afirma que es en el culto precisamente, ya sea por medio de ritos o de reflexiones profundas de la fe, donde el creyente experimenta sus creencias y es revestido de una fuerza sobrenatural que le permite prepararse para enfrentar su realidad cotidiana. ${ }^{62}$ Un elemento importante en el culto protestante es el canto, ya que este es uno de los medios más eficaces de captar el interés de las personas: proclamar la fe, infundir en el creyente el valor para resistir las vicisitudes de la existencia y generar esperanza. ${ }^{63} \mathrm{Al}$ igual que la himnología en la historia de la nación sirvió para cumplir el propósito de expresar la identidad de una comunidad imaginada, la práctica protestante de la himnología cumplió este fin en el campo religioso. ${ }^{64}$

\section{Liturgia}

En los primeros años del establecimiento de la Iglesia Presbiteriana se tradujeron himnos, para ser cantados en los cultos, y se siguió el modelo litúrgico de las iglesias europeas y estadounidenses, estos himnos traducidos expresaban sus respectivas realidades contextuales. ${ }^{65} \mathrm{La}$ influencia de los grandes avivamientos en los Estados Unidos de América se vio reflejada en mucha de la himnología, como se puede evidenciar en la letra del himno Que mi vida entera $e^{e s t e^{66}}$ que proclamaba la completa consagración a Dios y la vida de piedad. ${ }^{67}$ A su vez la himnología traída por los misioneros reflejaba sus imaginarios y

61 Daniel Salinas, Teología con alma latina: el pensamiento evangélico en el siglo XX (Lima, Perú: Puma, 2018), 13; Bourdieu, «Génesis y estructura...», 5; Kuyper, Lectures on Calvinism, 17.

62 Durkheim, Las formas elementales..., 388-389; Mackay, El sentido presbiteriano..., 205-213.

63 The Fifty-First Annual Report of the Board of Foreign Missions of the Presbyterian Church of the United States of America (New York: Presbyterian Church the USA, 1888), 41 (EV1); Mircea Eliade, Imágenes y simbolos. Ensayos sobre el simbolismo mágico-religioso, Versión española de Carmen Castro, $3^{\mathrm{a}}$ ed. (Madrid, España: Taurus, 1979), 19.

64 Diana Luz Ceballos Gómez, «Desde la formación de la República hasta el Radicalismo liberal (18301886)», en: Historia de Colombia. Todo lo que hay que saber, Luis Enrique Rodríguez Baquero, et al. (Bogotá, Colombia: Aguilar, Altea, Taurus, Alfaguara, 2011), 167.

65 Alvin Schutmaat, Culto cristiano (San José, Costa Rica: SEBILA, 1985), 1-9; Ordóñez, Historia del cristianismo..., 52. Gracias al trabajo de cooperación de los protestantes en Colombia, para este análisis se seleccionaron los himnos que fueron conocidos y cantados en las diferentes regiones del país, en la mayoría de las denominaciones, privilegiando la Iglesia Presbiteriana, en los periodos mencionados.

66 Robert C. Savage, comp., Himnos de fe y alabanza (Cúcuta, Colombia: El Sembrador, 1966), Himno 293.

67 José Míguez Bonino, Rostro del protestantismo latinoamericano (Buenos Aires - Grand Rapids, Argentina-USA: Nueva Creación, 1995), 39; Bronislaw Bazcko, Los imaginarios sociales (Buenos Aires, Argentina: Editorial Nueva Visión, 1991), 23; esto se puede apreciar en los testimonios de conversiones que narra Alexander M. Allan, «iCambiar de religión!», El Evangelista Colombiano, Serie XVII, n. ${ }^{\circ} 235$ (Bogotá: abril de 1931): 1 . 
representaciones optimistas, la fe en el progreso del mundo anglosajón, anterior a las dos guerras mundiales, y la convicción de que el mundo muy pronto abrazaría la fe cristiana. En las celebraciones de 1906 del primer cincuentenario de la Iglesia Presbiteriana en Colombia, Ordoñez registra que se entonaron las notas del himno Firmes y adelante ${ }^{68}$ que reflejó el carácter de una Iglesia pionera y militante, hija su época, así se expresa en la siguiente estrofa:

Al sagrado nombre de nuestro Adalid,

Tiembla el enemigo y huye de la lid.

Nuestra es la victoria, dad a Dios loor;

Y óiganlo el Averno, lleno de pavor.

En este himno, al igual que en la sociedad en general, ${ }^{69}$ se puede ver el optimismo con el que la Iglesia Protestante veía el futuro. En el campo de la teología se estaba dando el debate entre la teología liberal versus la teología conservadora, y los presbiterianos fueron actores principales en este; también, desde el siglo XVIII, ocuparon un lugar central las controversias sobre los conceptos milenaristas de orientación amilenarista, premilenarista o postmilenarista. ${ }^{70} \mathrm{La}$ Iglesia Presbiteriana históricamente se ha identificado con el amilenarismo; sin embargo, el postmilenarismo tuvo mucha acogida en la teología moderna de finales del siglo XIX e inicios del siglo XX, teología que tuvo su auge antes de las dos confrontaciones mundiales. ${ }^{71} \mathrm{El}$ postmilenarismo se basó en las teorías de los procesos evolutivos y, por lo tanto, fue acogido en el pensamiento teológico liberal que se identificó con las teorías evolucionistas de su época. Esta doctrina creía que, gracias a los esfuerzos humanos, los avances científicos y las reformas político-sociales, la humanidad iba a establecer progresivamente una sociedad ideal, que el reino de Dios sería introducido en el mundo y la humanidad sería

68 Savage, Himnos..., 247.

69 Joyce Appleby, Lynn Hut y Margaret Jacob, Telling the Truth about History (New York - London, USAUK: W.W. Norton \& Company, 1994), 15-50; Robert Nisbet, Historia de la Idea de Progreso, Trad. de Enrique Hegewicz, $2^{\mathrm{a}}$ ed. (Barcelona, España: Gedisa, 1991); Diana Luz Ceballos Gómez, Simbolismo y saber: el circuito de la cultura (Medellín, Colombia: Universidad Nacional de Colombia, 2018), 1-28.

70 Los que proclamaron que un reino milenario se inauguraría con la segunda venida de Cristo antes del juicio final se denominaron premilenaristas, los que creyeron en la segunda venida de Cristo después de la formación de una época dorada de término indefinido gracias a la cristianización del mundo provocada por la predicación del evangelio se denominaron postmilenaristas, y los que creyeron que en la Biblia no había suficiente evidencia para la idea de un reino milenario político en la tierra anterior al juicio final se denominaron amilenaristas, posición más aceptada por el presbiterianismo; Gordon R. Lewis y Bruce A. Demarest, Integrative Theology. Spirit-Given Life: Good's People Present and Future, Vol. 3 (Grand Rapids, USA: Zondervan, 1994), 371-386.

71 Adam Petersen, «The Premillennial Menace: Shailer Mathews Theological-Political Battle Against Premillennialism During the First World War», Journal of Church \& State, vol. 60, n. ${ }^{\circ} 2$ (2018): 271-298, https:// doi.org/10.1093/jes/csx051. 
atraída a Cristo antes de su segunda venida. ${ }^{72}$ Estas enseñanzas presentaban un optimismo desmedido en la ciencia y una confianza ciega en la bondad humana, propias del mundo moderno. Este sentimiento de optimismo no fue ajeno a la Iglesia Presbiteriana que en las dos primeras décadas del siglo XX experimentó un sentimiento de optimismo por la avanzada estadounidense en América Latina. ${ }^{73}$ Aunque el ambiente de optimismo y triunfalismo hacía parte del sentimiento inherente de la Iglesia en este período, la tradición pietista de la iglesia evangélica en América Latina se identificó en su mayoría con el premilenarismo ${ }^{74}$ y la Iglesia Presbiteriana no fue ajena a la influencia de esta orientación teológica que también tuvo acogida en algunos sectores de la denominación. Este es un ejemplo que evidenció un distanciamiento con la declaración de fe, cuestión fundamental para una iglesia confesional. No es de extrañar que la pérdida de identidad teológica fuera uno de los factores que llevaron a la división de la iglesia en $1993 .^{75}$

Los presbiterianos, conscientes de que los cantos eran una de las formas más eficaces de difundir la fe y discipular; ${ }^{76}$ ya para inicios del siglo XX habían desarrollado una cultura musical en sus feligreses. ${ }^{77}$ Los presbiterianos latinoamericanos contribuyeron al desarrollo de la himnología para las iglesias del continente, un ejemplo de ello fue el caso de Vicente Mendoza, quien compuso en 1920 el conocido himno Jesús es mi rey soberano. ${ }^{78}$ En 1947 Mariano Beltrán adaptó una melodía de corrido mexicano al himno Cuán gloriosa será la maña$n a .{ }^{79}$ Otro compositor que contribuyó al desarrollo de la himnología latinoameri-

72 Louis Berkhof, Teología Sistemática, Trad. de Felipe Delgado Cortés (Jenison, EE. UU.: TELL, 1988), 849-862; John. F. Walvoord, «Postmillennialism», Bibliotheca sacra, vol. 106, n. ${ }^{\circ} 422$ (1949): 149-168; James H. Moorhead, «The erosion of postmillennialism in American religious thought, 1865-1925», Church History, vol. 53, n. ${ }^{\circ} 1$ (1984): 61-77, https://doi.org/10.2307/3165956.

73 Mario Aguilera, «La secesión de Panamá: noviembre 3 de 1903», Banrepcultural, https://www.banrepcultural.org/biblioteca-virtual/credencial-historia/numero-117/la-secesion-de-panama-noviembre-3-de-1903.

74 Sin embargo, esta iglesia aferrada a la teología premilenarista, en las últimas décadas, ha tenido un cambio en su praxis que ahora es más cercana a la concepción optimista del posmilenarismo, muy posiblemente generada por su crecimiento exponencial y su creciente aumento de influencia en el entorno político y económico. La paradoja de esta iglesia es que, aunque su predicación está fundamentada en la teología premilenarista, su praxis refleja los imaginarios del posmilenarismo.

75 AIPC, Informativo Sinódico, Bogotá, 16 de junio de 1989, f. 2; Roberto Argel, entrevistado por Luis Eduardo Ramírez, Medellín, septiembre 18 de 2015, comentó que muchos de estos cambios doctrinales se debieron a la pérdida de líderes y a la incorporación de pastores de otras denominaciones que no asimilaron el presbiterianismo.

76 Timoteo Anderson Carlson, «Reflexiones sobre la alabanza y la adoración a través de la historia», en Primera Iglesia Presbiteriana de Bogotá, Príncipe de Paz 150 años, dir. Germán Ezequiel Suárez Núñez (Bogotá, Colombia: Buena semilla, 2006), 140.

77 Alexander M. Allan, Recuerdos 1910-1945 (Medellín: Unión, S.f.), 1; Archivo Iglesia Presbiteriana Central de Bogotá, Príncipe de Paz - AIPCB - El Nuevo Himnario Evangélico, (New York: Sociedad Americana de Tratados, 1915).

78 Anderson, «Reflexiones sobre la alabanza...», 143-144; Schutmaat, Alvin, Culto Cristiano (San José, Costa Rica: SEBILA, 1985), 43.

79 Anderson, «Reflexiones sobre la alabanza...», 146; Valentín González B., Patricio Symes. Vida y obra de un pionero (Bogotá, Colombia: Iglesia Cruzada Cristiana, 2000), 107-108. 
cana, con gran variedad de obras, fue el guatemalteco Alfredo Colom, su música fue ampliamente conocida y cantada por la Iglesia colombiana; dice Schutmaat, que Colom fue el precursor del movimiento musical de los años 60 y 70 cuando hicieron aparición himnos con alma latinoamericana. ${ }^{80}$

A mediados del siglo pasado, el tema más importante de los evangélicos fue la segunda venida de Cristo $^{81}$ y esto se vio reflejado en su himnología, un ejemplo son los himnos La venida de Cristo y Yo soy un pobre peregrino, ${ }^{82}$ que proclamaban el sufrimiento del cristiano en la tierra, el inminente retorno de Cristo y el galardón celestial. Esta himnología preparaba a la feligresía para afrontar con resignación la persecución, teniendo en mente la esperanza futura de una recompensa celestial, tema propicio en medio de la persecución que soportaba Iglesia Protestante colombiana ${ }^{83}$ y que se agudizó a partir del asesinato de Jorge Eliecer Gaitán el 9 de abril de $1948 .{ }^{84}$ Aunque la Constitución 1886 permitió el ejercicio de otros cultos que no fueran contarios a la moral cristiana ni a las leyes, desde 1948 hasta 1958 este fue restringido, se prohibió a los protestantes hacer proselitismo, y se limitó su labor educativa ${ }^{85}$ Un estudio comprehensivo sobre la persecución religiosa en Colombia lo realizó el ministro presbiteriano James E. Goff. ${ }^{86}$

En el periodo de la violencia, la Iglesia Evangélica fortaleció su unidad; en 1950 en Medellín, en el Seminario Bíblico de Colombia, se dio inicio a las reuniones interdenominacionales llamadas «Convención de la Vida Victoriosa». ${ }^{87}$ Estas reuniones fueron espacios para cuidar y servir a la iglesia sufriente, se entonaron himnos con mensajes de consagración, avivamiento y esperanza como

80 Schutmaat, Culto Cristiano (San José: SEBILA, 1985), 43-44. La música de Colom se difundió a través de los himnarios: Himnos de la vida cristiana, Himnario Bautista, Himnario de fe y alabanza y Celebremos su gloria. Estos himnarios fueron conocidos y usados en los cultos de las congregaciones locales de la Iglesia Presbiteriana y en la mayoría de Iglesias Evangélicas en Colombia.

81 Daniel Salinas, «Historical Perspective on Evangelism and Discipleship in Latin America», Latin America Evangelist, vol. 86, n. ${ }^{\circ} 1$ (marzo-junio, 2006): 6.

82 Savage, Himnos..., 148 y 304.

83 Miguel Ángel Builes, «La corrupción avanza. Febrero 24 de 1953», en: Cartas pastorales, Miguel Ángel Builes (Bogotá, Colombia: Empresa Nacional de Publicaciones, 1957), 233-237; Ángela Uribe Botero, «¿Puede el uso de metáforas ser peligroso? Sobre las pastorales del monseñor Miguel Ángel Builes», Revista de Estudios Sociales, n. 34 (diciembre, 2009): 114.

84 Ignacio Guevara, Paria solitario: de niño de la calle a apóstol de Jesús (Bogotá, Colombia: La Buena Semilla, 2006), 90-96.

85 Bucana, La Iglesia evangélica..., 132-134; Juan Diego Demera Vargas y Aida Patricia Rodríguez Leuro, «Minorías religiosas y persecución protestante. Colombia 1948-1957», en: Confesionalidad y política. confrontaciones multiculturales por el monopolio religioso, ed. Carlos Vladimir Zambrano, $2^{\mathrm{a}}$ ed. (Bogotá, Colombia: Universidad Nacional de Colombia, 2003), 295-312; Ospina, Las sectas protestantes ..., 26.

86 James E. Goff, The Persecution of Protestant Christians in Colombia, 1948-1958, Sondeos, No. 23, (Cuernavaca, México: CIDOC, 1968); Archivo Iglesia Presbiteriana Central de Bogotá —Príncipe de Paz(AIPCB), Acta 15 (Bogotá: marzo 2 de 1948) folio14; González, Patricio Symes, 111-125; F. W. Shillingsburg, La llama que nunca se apaga. Breve historia de la Unión Misionera Evangélica durante sus setenta y cinco años de mantener en alto la llama, 1908-1983 (Cali, Colombia: Aurora, 1983), 91-104; Ordóñez, Historia del cristianismo..., 478-482; Bucana, La Iglesia evangélica ..., 129-164.

87 Guevara, Paria solitario..., 108-117. 
Salvador, a ti me rindo ${ }^{88}$. El contexto de persecución fue también un tiempo de avivamiento para la Iglesia Protestante colombiana, que se identificó con los movimientos de santidad y de evangelización. ${ }^{89}$ Con la llegada de los misioneros de la Oriental Missionary Society-OMS-, Benjamín H. Pearson y Bill Gillam se inició el modelo de campañas evangelísticas, modelo que también fue adoptado por los presbiterianos..$^{90}$

El gobierno de Laureano Gómez (1950-1951) fue difícil para las iglesias de corte protestante; ${ }^{91}$ que vieron la llegada de general Gustavo Rojas Pinilla al poder en 1953 con esperanza, pero pronto su gobierno fue contrario a la libertad de culto y cercano a la Iglesia Católica, so pretexto de devolver la paz a Colombia. ${ }^{92}$ Aún más, el gobierno del general Rojas Pinilla vio con desconfianza las labores de estas iglesias, y las llegó a relacionar con los movimientos subversivos, quizás por las relaciones del protestantismo histórico con el discursos del evangelio social. ${ }^{93}$ Como los protestantes habían hecho una autocrítica interna de que la iglesia carecía de un compromiso con el evangelio social, ${ }^{94}$ no fue coincidencia que en este periodo estas iglesias interesadas en temas sociales se identificaran con el mensaje de defensa de las clases oprimidas y apoyaran los movimientos de la Unión de Ligas Juveniles Evangélicas Latinoamericanas -ULAJE- organizado en 1941 y el Consejo Mundial de Iglesias -CMI- organizado en 1948, la Comisión Latinoamericana de Educación Cristiana-CELADEC- en 1962 y el Movimiento Misión Urbana e Industria -MISUR- en $1963 .{ }^{95}$ Los presbiterianos interesados en estos temas participaron activamente en la mayoría de estos movimientos. ${ }^{96}$

En el Congreso Misionero de Edimburgo (CMI) (1910), las Conferencias Evangélicas Latinoamericanas (CELA II, Lima 1961 y CELA III, Buenos Aires $1969)^{97}$ se identificaron con el ecumenismo alejándose del fervor evangelístico propio de las iglesia evangélicas latinoamericanas..$^{98} \mathrm{El}$ pensamiento ecuménico

88 Savage, Himno..., 294.

89 Guevara, Paria solitario..., 110 y 112.

90 Robert D. Wood, In These Mortal Hands. The Story of the Oriental Missionary Society. The First 50 Years (Greenwood, USA: OMS International, 1983), 295.

91 Wood, In These Mortal Hands..., 300-311; González, Patricio Symes..., 121-124.

92 González, Patricio Symes..., 127-132.

93 Wood, In These Mortal Hands, 307-308; Gabriel Cabrera Becerra, Los poderes en la frontera. Misiones católicas y protestantes, y Estados en el Vaupés colombo-brasileño, 1923-1989 (Medellín, Colombia: Universidad Nacional de Colombia, 2015), 37; Goff, The Persecution of Protestant, 3/27-3/36; Jesús David Quintero Aleans, Heretical Protestant Millionaires are pouring their Money into Colombia. El Trato a las minorías religiosas, 1948-1953, Trabajo para optar al título de historiador (Bogotá, Colombia: Pontificia Universidad Javeriana, 2012), 107-116; Bucana, La Iglesia evangélica ..., 131.

94 Rodríguez, Hacia una historia ..., 232-233.

95 Escobar, «Los movimientos de cooperación...», 104.

96 Helis Barraza, entrevistado por Luis Eduardo Ramírez, Medellín. junio 25 de 2016.

97 Escobar, «Los movimientos de cooperación», 103; Escobar, «¿Qué significa ser evangélico hoy?», 36-37.

98 José Míguez Bonino, Conflicto y Unidad en la Iglesia (San José, Costa Rica: SEBILA, 1992) 60-75; Jean Pierre Bastian, Protestantismo y modernidad latinoamericana. Historia de unas minorías religiosas 
en el continente se difundió a través de la revista Cuadernos Teológicos fundada en $1950 .{ }^{99}$ El Movimiento Iglesia y Sociedad en América Latina (ISAL, 1982) nació de los CELA II y III, y fundó la revista Cristianismo y Sociedad. ${ }^{100}$ Como dice José Míguez Bonino, todas estas corrientes fueron gestoras de la teología de la liberación en América Latina. ${ }^{101}$

En la Iglesia Católica este periodo fue determinado por el Concilio Vaticano II (1962-1965) que tuvo el propósito de renovar la Iglesia para que respondiera a los desafíos de mundo moderno. El Concilio promovió un culto más contextualizado en los idiomas vernáculos y el diálogo ecuménico con otras iglesias cristianas. ${ }^{102}$ La Segunda Conferencia General del Episcopado Latinoamericano en Medellín-CELAM II- (1968) tuvo como objetivo la aplicación del Vaticano II, con un énfasis en la pastoral social que se identificaba con los pobres y sus luchas político-sociales. ${ }^{103}$

Para la década del 70, el movimiento de evangelio social ya había generado su propia himnología acorde con su realidad contextual y con la opción por los pobres. ${ }^{104}$ Como lo expresa el Himno En medio de la vida: ${ }^{105}$

Tú estás en el trabajo del campo y la ciudad

Y es himno de la vida el diario trajinar.

activas en América Latina (México, D.F.: FCE, 1994), 205. Escobar, «Los movimientos de cooperación...», 104. Samuel Escobar, La Fe Evangélica y las Teologías de la Liberación (E1 Paso, EE. UU.: Casa Bautista de Publicaciones, 1987), 54.

99 Escobar, La fe evangélica..., 55.

100 Escobar, La fe evangélica..., 57-58; Emilio A. Núñez, Teología de la liberación. Una perspectiva evangélica (San José, Costa Rica: Caribe, 1986), 49-77. Bastian, Protestantismo y modernidad..., 233 y 238, 240. Álvarez, Carmelo E. y Pablo Legget, eds., Lectura teológica del tiempo latinoamericano: Ensayos en honor del Dr. Wilton M. Nelson (San José, Costa Rica: Seminario Bíblico Latinoamericano, 1979), 149194. Castillo Cárdenas, Gonzalo e Isay Pérez Benavides, La influencia religiosa en la conciencia social de Orlando Fals Borda (Barranquilla, Colombia: Corporación Universitaria Reformada, 2010), 51-53. Jairo Roa, «El desarrollo desde la perspectiva de la teología en América Latina», en Diversidad y dinámicas del cristianismo en América Latina, comp., Andrés Eduardo González Santos (Bogotá, Colombia; Bonaventuriana, 2007), 69-127.

101 José Míguez Bonino, «Las iglesias protestantes y evangélicas en América Latina y el Caribe: un ensayo interpretativo», Cuadernos de Teología, Vol. XIV, No. 2 (1995): 34-35.

102 Concilio Vaticano II, Constitución pastoral Gaudium et Spes, Sobre la Iglesia en el mundo moderno, $4^{\mathrm{a}}$ edición (Bogotá, Colombia: Ediciones Paulinas, 1970), 147-246; Concilio Vaticano II, Constitución Sacrosanctum Concilium, Sobre la sagrada Liturgia, $4^{\mathrm{a}}$ edición (Bogotá, Colombia: Ediciones Paulinas, 1970), 111-146; Concilio Vaticano II, Declaración Dignitatis Humanae, Sobre la libertad religiosa, $4^{\mathrm{a}}$ edición (Bogotá, Colombia: Ediciones Paulinas, 1970), 470-483; Concilio Vaticano II, Decreto Unitatis Redintegratio, Sobre el ecumenismo, $4^{a}$ edición (Bogotá, Colombia: Ediciones Paulinas, 1970), 313-314; Justo L. González, Historia del cristianismo: desde la era de la reforma hasta la era inconclusa, Tomo 2 (Miami, Florida: UNILIT, 1994), 517-519;

103 II Conferencia General del Episcopado Latinoamericano, Medellín Conclusiones, La Iglesia en la actual transformación de América Latina a la luz del Concilio (Medellín, Colombia: CELAM, 1968), 103-107.

104 El ala progresista de la Iglesia Presbiteriana de Colombia difundió esta música a través de corarios elaborados por las iglesias locales.

105 Seminario Bíblico Latinoamericano, comp. Celebremos Juntos (San José, Costa Rica: SEBILA, 1989), Himno 79. 
El mensaje de esta corriente teológica fue muy diferente al mensaje de los protestantes influenciados por los movimientos de santidad. Aquí la esperanza no estaba en el cielo ni el galardón para la otra vida. La experiencia de fe tenía que ver con el cuidado del pobre, la adoración no era mística, sino que se manifestaba en la labor diaria del obrero. Dios no estaba confinado al lugar sagrado, sino que se hacía presente en los acontecimientos de la vida cotidiana. Esta himnología mostró la faceta más humana de Dios, cercana al pueblo, al obrero y al pobre. Este fue el tema recurrente en las comunidades liberacionistas, como lo expresa la siguiente estrofa del himno El Dios de los pobres: ${ }^{106}$

$$
\begin{aligned}
& \text { Vos sos el Dios de los pobres, } \\
& \text { el Dios humano y sencillo, } \\
& \text { el Dios que suda en la calle, } \\
& \text { el Dios de rostro curtido, } \\
& \text { por eso es que te hablo yo, } \\
& \text { así como habla mi pueblo (bis). } \\
& \text { Porque sos el Dios obrero, } \\
& \text { el Cristo trabajador. }
\end{aligned}
$$

La teología de la liberación fue militante y en su quehacer hermenéutico combinó el mensaje del evangelio con los postulados y metodologías marxistas, ${ }^{107}$ lo que causó choques dentro de la Iglesia Presbiteriana entre las facciones conservadoras y liberacionistas. ${ }^{108}$ Lo paradójico fue que mientras la opción de

106 Seminario Bíblico Latinoamericano, Himno 78, canto de la misa campesina nicaragüense.

107 Samuel Escobar, «La fundación de la Fraternidad Teológica Latinoamericana: breve ensayo histórico», Boletín Teológico, año 27, n. ${ }^{\circ}$ 59-60 (julio-diciembre, 1995): 10-11, «Del lado ecuménico, el movimiento Iglesia y sociedad en América Latina (ISAL), que surge de una consulta en Huampaní en el año 1961, representaba la radicalización del pensamiento protestante histórico que se agudizó en el transcurso de la década. [...] Ni Arana ni Padilla, ni la mayoría de otros teólogos evangélicos que fundaron la FTL podrían ser descritos como fundamentalistas, pero sí se consideraban evangélicos cuya posición teológica difería en varios puntos de la que venían expresando los teólogos de ISAL. Estos evangélicos no creían necesario adoptar el marxismo como método de análisis de la realidad social, ni compartían la fe de que el mundo estaba marchando hacia el socialismo, pero tampoco compartían el anti-comunismo ingenuo de los misioneros conservadores»).

108 Helis (EV3) Barraza, entrevistado por Luis Eduardo Ramírez, Medellín, junio 25 de 2016: «después del centenario de la Iglesia Presbiteriana en Colombia, esta pasa de ser una iglesia convocante y confesante por utilizar la frase de Bonhoeffer, a ser una iglesia fundadora de organismos como CCPAL que después viene a ser AIPRAL y de la Confederación Evangélica Colombiana. Porque la vocación ecuménica de esos líderes que estaban en los 60 formando parte de la ROSCA, un grupo de investigación social, conformada por Falls Borda y Gonzalo Castillo, apoyados por líderes como el Dr. Alfonso Lloreda, pastor de la Iglesia Central de Barranquilla, son expulsados de la Iglesia a comienzo de los 60 porque en el marco de la Guerra Fría eran considerados auspiciadores del comunismo»; Archivo Iglesia Evangélica Presbiteriana 
la teología de la liberación fue por los pobres, la opción de los pobres fue por el pentecostalismo. ${ }^{109}$

Por otro lado, en las décadas de los sesenta y setenta, las Iglesias Protestantes de corte evangélico que se diferenciaban del CMI, inspiradas en las multitudinarias cruzadas evangelísticas de Billy Graham, consolidaron un programa de evangelización masiva denominado «Evangelismo a Fondo», organizado por la Alianza Evangélica de Costa Rica y la Confederación Evangélica de Colombia-CEDECOL-. ${ }^{110}$ Este programa revolucionó los métodos de evangelización usados hasta la fecha por las Iglesias Protestantes en América Latina. ${ }^{111}$ El 8 de diciembre de 1966 se realizó en Bogotá una campaña multitudinaria con el evangelista Luis Palau. ${ }^{112}$ En estas décadas la iglesia promovió ministerios evangelísticos, introdujo nuevos estilos de alabanza y se abrió al movimiento carismático, lo cual fue determinante para su crecimiento exponencial. Es importante hacer referencia a la himnología de ritmos populares cantada por las iglesias evangélicas en zonas rurales; desde 1972 ministerios musicales como los Voceros de Cristo ${ }^{113}$ popularizaron himnos como Escogido fui de Dios y Loor a ti mi Dios; también desde la década del 60 se introdujo la práctica de cantar los Salmos con melodías frescas. Estos movimientos y estilos de alabanza tuvieron acogida en amplios sectores de la Iglesia Presbiteriana colombiana. ${ }^{114}$

La expresión evangélica de la Iglesia Protestante latinoamericana fue muy cercana a los movimientos evangélicos estadounidenses, un organismo que representó este movimiento fue el Consejo Cristiano Internacional-CCI-, organizado en 1951 en Holanda. La revista Pensamiento Cristiano (1953) fue el medio de difusión del mensaje evangélico protestantes. ${ }^{115}$ También la revista Christianity Today, comprometida con la evangelización mundial, organizó en 1966 el Congreso Mundial de Evangelización-CME- en Berlín y el encuentro de Lausana en 1974. En Latinoamérica se realizó en Bogotá en 1969 el Congreso Latinoamericano de Evangelización -CLADE I-, con el objetivo de promover

de Medellín (AIEPM), Acta 12 de 1985 (Medellín: agosto 24 de 1985) folios 475-476; Dayro Aranzalez e Isaí Pérez, entrevistados por Luis Eduardo Ramírez, Medellín, junio15 de 2018.

109 Richard Shaull, «La Iglesia, crisis y nuevas perspectivas», Vida y Pensamiento, vol. 15, n. ${ }^{\circ} 2$ (1995): 8-48.

110 Dayton W. Roberts, Los auténticos revolucionarios: la historia de Evangelismo a Fondo en América Lati$n a$, Trad. de José María Blanch (San José, Costa Rica: Caribe, 1969); como lo describe Shillingsburg, La llama ..., 123. Bastian, Protestantismo y modernidad ..., 208-209 y 240-246.

111 Jean Pierre Bastian, Protestantismo y modernidad latinoamericana. Historia de unas minorías religiosas activas en América Latina (México, D.F.: FCE, 1994), 208-209 y 240-246; Shillingsburg, La llama..., 121-124; González, Patricio Symes..., 181-182; Escobar, «La fundación de la Fraternidad...», 12. Archivo Iglesia Presbiteriana Central de Bogotá - Príncipe de Paz - (AIPCB), Acta 104 Campaña de avivamiento para octubre 19-21 de 1973 (Bogotá: octubre 8 de 1973) folio 186.

112 Shillingsburg, La llama ..., 123.

113 Los Voceros de Cristo, en http://www.losvocerosdecristo.com/somos.php, ver Musica.com, en https:// www.musica.com/letras.asp?biografia $=22757$.

114 Javier Voelkel, entrevistado por Luis Eduardo Ramírez, Medellín, julio 13 de 2015 y agosto 16 de 2017.

115 Bastian, Protestantismo y modernidad..., 206; McGrath, Alister, Evangelicalism \& the Future of Christianity (Downers Grove: Intervarsity Press, 1995), 53-87. 
la cooperación para la evangelización. ${ }^{116}$ Cabe resaltar el papel de la Fraternidad Teológica Latinoamericana -FTL- como el movimiento que promovió la reflexión teológica con el fervor evangélico latinoamericano. ${ }^{117}$

En reacción al modelo estructurado de la Iglesia de corte anglosajón de los protestantes históricos y a la militancia de transformación de las estructuras sociales de los movimientos comprometidos con el evangelio social, el movimiento pentecostal, ${ }^{118}$ en la década del 80 , contribuyó con una alabanza fresca y sencilla, que ponía énfasis en la obra del Espíritu Santo y sus dones ${ }^{119}$ como lo expresa el coro Alguien está aquí, ${ }^{120}$ donde Cristo si está cerca, pero no como el camarada revolucionario proclamado por la teología de la liberación, sino como el ser divino que bautiza con el Espíritu Santo y reparte dones espirituales. La fe pentecostal cree en un Cristo de poder, en el obrar de los ángeles defendiendo al cristiano y ayudándolo a vencer en medio de las penurias diarias de la vida. Contrario a las expresiones anteriores, el mundo espiritual en la fe pentecostal es parte de la realidad y todo lo que vive el creyente tiene connotaciones espirituales. El movimiento pentecostal no fue ajeno a la Iglesia Presbiteriana en Colombia, muchas de sus iglesias adoptaron las liturgias pentecostales en sus cultos. ${ }^{121}$ Uno de los casos de más resonancia fue el sucedido en la Iglesia Pres-

116 Escobar, «Los movimientos de cooperación...», 105; Escobar, La fe evangélica ..., 57-59.

117 Escobar, «Los movimientos de cooperación...», 106. Escobar, La fe evangélica ..., 59-63. Bastian, Protestantismo y modernidad..., 233.

118 William Beltrán, «El evangelicalismo y el movimiento pentecostal en Colombia en el siglo XX», en: Historia del cristianismo en Colombia: corrientes y diversidad, dir., Ana María Bidegain (Bogotá, Colombia: Taurus, 2004), 451-455; William Mauricio Beltrán Cely, «La expansión pentecostal en Colombia», en: El pentecostalismo en Colombia. Prácticas religiosas, liderazgo y participación política, ed., Clemencia Tejeiro Sarmiento, (Bogotá, Colombia: Universidad Nacional de Colombia - CES, 2010), 73-96; William Mauricio Beltrán Cely, «Pluralización religiosa y cambio social en Colombia», Theologica Xaveriana, $\mathrm{n}$. 175, Pontificia Universidad Javeriana, Bogotá (enero-junio, 2013): 57-85, https://repositorio.unal.edu.co/ handle/unal/75037; William Mauricio Beltrán Cely, «Del porque los pentecostalismos no son protestantismos», Creer y poder hoy, memorias de la cátedra Manuel Ancízar (Bogotá: Universidad Nacional de Colombia, 2007), 469-485, https://repositorio.unal.edu.co/handle/unal/10737; Richard Shaull «El quehacer teológico en el contexto de sobrevivencia en Abya-Yala», en Por una sociedad donde quepan todos, ed., Duque, José (San José, Costa Rica: DEI, 1996), 87-105; Clemencia Tejeiro Sarmiento, «El pentecostalismo en el contexto del cambio social y religioso en América Latina y Colombia», en El pentecostalismo en Colombia. Prácticas religiosas, liderazgo y participación política, ed., Tejeiro Sarmiento, Clemencia (Bogotá: Universidad Nacional de Colombia - CES, 2010), 15-27. El pentecostalismo surgió a inicios del siglo XX como movimiento de avivamiento dentro de las iglesias clásicas y como respuesta a los postulados de la Ilustración, la modernidad, el evolucionismo y ateísmo, que habían permeado la iglesia a través de la teología liberal.

119 Loida Sardiñas Iglesias, «Iglesias, identidad y plurirreligiosidad: una mirada al protestantismo histórico», Albertus Magnus, vol. 7, n. ${ }^{\circ} 2$ (2016): 268, https://doi.org/10.15332/s2011-9771.2016.0002.04.

120 Ebenezer Honduras, «Alguien está aquí», https://genius.com/Ebenezer-honduras-alguien-esta-aqui-lyrics, Consultada el 6 de junio de 2019.

121 Sara Vanegas, entrevistada por Luis Eduardo Ramírez (Medellín: diciembre 27 de 2016): «El movimiento carismático pentecostal ha influido en la Iglesia Presbiteriana especial en el Presbiterio del Sur, allí en estas iglesias hubo más influencia en este aspecto porque la gente fue muy dada a seguir las estructuras de los pentecostales. Pensaron que si imitaban a los pentecostales eso iba a traer crecimiento a la iglesia»; Helis Barraza, entrevistado por Luis Eduardo Ramírez, Medellín, junio 25 de 2016: «El asunto de la liturgia generó una tensión muy fuerte porque en presbiterios como el de la Costa y el Central, que estaban más 
biteriana Central de Ibagué, que en 1975 se dividió por temas de manifestación carismáticas, surgiendo la Segunda Iglesia Presbiteriana de Ibagué que mantuvo una línea más tradicional. ${ }^{122}$

El presbiterianismo pudo experimentar la influencia de estos movimientos, debido a que su forma de adorar no se redujo a un tipo o estilo de liturgia:

[Los presbiterianos] adoran en diferentes formas, desde la tradicional a la contemporánea; sostienen una gran variedad de puntos de vista en asuntos políticos, sociales y teológicos. De hecho a los presbiterianos se les exhorta a emprender diálogos y debates entre sí mismos como un medio para determinar la voluntad de Dios para la humanidad [...]. Son una iglesia con muchos estilos y prácticas, para gente de muchos orígenes, unidos por su fe en Jesucristo. ${ }^{123}$

\section{Los templos}

El lugar del culto tomó un papel importante en la visión presbiteriana, ya lo expresaba Eliade que para el ser religioso el espacio no es homogéneo. ${ }^{124} \mathrm{Sin}$ embargo, los templos presbiterianos en Colombia siguieron la tradición presbiteriana europea de minimalismo y sencillez. En la tradición protestante se eliminaron las imágenes, lo que se conoció como la controversia iconoclasta. ${ }^{125}$

La arquitectura de la Reforma en sus primeras décadas en Europa no cambió a la de la Iglesia Católica, los templos se adaptaron y se introdujeron cambios litúrgicos, donde la centralidad de la Escritura jugó un papel predominante, este énfasis en la predicación de la Biblia implicó una arquitectura que diera prioridad a que la congregación pudiera escuchar y entender con claridad el mensaje que debía ser predicado en la lengua vernácula. El púlpito tomó el lugar central en el interior de los templos protestantes desplazando la mesa sacramental que era lo central en la Iglesia Católica. Como se desplazó el ritual ceremonial por la exposición inteligible de las Escrituras, se introdujeron las bancas en los templos protestantes. Fundamentados en la doctrina del sacerdocio de todos los creyentes, la comunidad comenzó a participar activamente en los servicios y el culto ya

dados al culto europeo, ceremonioso y centrado en la Palabra, comenzaron a entrar prácticas religiosas que chocaban con este ritual. Temas como el de las lenguas, las vigilias y los ayunos, expresiones carismáticas que caracterizaban al movimiento pentecostal, generaron tremendas tensiones al interior de la iglesia».

122 Uriel Aguirre, entrevistado por Luis Eduardo Ramírez, Medellín, diciembre 23 de 2016.

123 PCUSA, "Who Are We Presbyterians», Video de Youtube, 17:32, publicado el 8 julio de 2016, https:// www.youtube.com/watch? $=1 Z J c W N U m v f c$.

124 Mircea Eliade, Lo sagrado y lo profano, Trad. de Luis Gil, 4ª ed. (Barcelona, España: Guadarrama/Punto Omega, 1981), 15-17.

125 El movimiento iconoclasta estaba en contra del culto a las imágenes. Muchas de las Iglesias Protestantes toman como base Éxodo 20:4-6 para rechazar cualquier uso de imagen en sus templos. Ver sobre la controversia iconoclasta: Peter Toon, «Controversia de la iconoclastia», en Diccionario de la Historia de la Iglesia, Nelson, Wilton M. (Miami, Florida: Caribe, 1989), 542-543; Inst. I, xi, 12-13. 
no estuvo centrado en el sacerdote mediador de la gracia sacramental. ${ }^{126} \mathrm{El}$ canto congregacional fue un aspecto característico de la liturgia protestante; por eso se desarrollaron grupos corales en cada congregación, el órgano y el piano llegaron a ser instrumentos muy usados en la liturgia. ${ }^{127}$

El énfasis en la exposición de las Escrituras para los reformadores y para las Iglesias Presbiterianas estaba muy relacionado con el énfasis en la educación, el presbiteriano debía saber leer porque era el medio directo para entender su fe. ${ }^{128}$ En el culto leer, cantar y entender la Palabra fue un acto revolucionario, donde toda persona tenía la capacidad de entenderla e interpretarla. ${ }^{29}$ Para el reformador Juan Calvino, el contenido de la predicación debía ser la Biblia. ${ }^{130} \mathrm{La}$ labor del predicador era exponer fielmente las Escrituras, pues este era el medio que el Señor instituyó para edificar su Iglesia y escuchar su voz. ${ }^{131}$ Dios se hacía presente no por el rito, sino por la exposición de la Palabra. Este principio teológico se vio reflejado en la arquitectura de los templos. Como lo resume Chiquete:

La arquitectura protestante se volvió hacia el intento de destacar los aspectos racionales y funcionales de los templos, evitando expresiones emotivas extremas. Las paredes desnudas y el ambiente de austeridad buscaban centrar la atención del oyente en la predicación y evitaban cualquier elemento dispersivo de la atención. ${ }^{132}$

La Iglesia Presbiteriana en Colombia comenzó la construcción de templos teniendo en cuenta esta teología de la centralidad de las Escrituras, el sacerdocio de todos los creyentes y el carácter no sacrificial de su culto. ${ }^{133}$ El 20 de septiembre de 1925 se inauguró el templo de la Iglesia Presbiteriana Central de Barranquilla, «que fue el primer edificio construido en Colombia para tal fin»; ${ }^{134}$ 35 años después de la organización de la Iglesia, el 5 de enero de $1890 .{ }^{135} \mathrm{En}$

126 Weber, 148-149: «Para el católico, la gracia sacramental de su Iglesia estaba a su disposición como medio de compensar su propia insuficiencia: el sacerdote era el mago que realizaba el milagro del cambio y que tenía en sus manos el poder de las llaves; se podía acudir a él con humildad y arrepentimiento, y él administraba penitencias y otorgaba esperanzas de gracia, seguridad de perdón [...]».

127 Daniel Chiquete, «Arquitectura cristiana: características y significados», en Arte, liturgia y teología, eds. Barreda Toscano, Juan José y Edesio Sánchez Cetina (Lima, Perú: Puma, 2013), 98-102.

128 Jaime Jaramillo Uribe, Historia de la pedagogía como historia de la cultura, $2^{\mathrm{a}}$ ed. (Bogotá, Colombia: Centro de Investigación y Educación Cooperativas - CIEC, 1978), 53-54.

129 Troeltsch, El Protestantismo..., 19-20; López, La estirpe calvinista..., 77-81; ver lo que se dice sobre las confesiones de fe en Joachim Guhrt, «La confesión de fe y su formación en la actualidad», Diálogo Ecuménico, Tomo XX, No. 68 (1985): 374; R. C. Sproul, Escogido por Dios, Trad. de Demetrio Cánovas Moreno (Miami, Florida: Unilit, 1993).

130 Donner, Una Introducción..., 139.

131 Inst. IV, i, 5.

132 Chiquete, «Arquitectura cristiana...», 100.

133 Ibíd., 98.

134 Ordóñez, 86; Bucana, La Iglesia evangélica ..., 65-67.

135 La organización de una Iglesia Presbiteriana se realiza bajo la autoridad de un presbiterio llenando algunos requisitos como una membrecía ya sea por bautismo, profesión de fe o transferencia, tener un cuerpo de 
Bogotá, el culto de organización de la Primera Iglesia Presbiteriana se llevó a cabo el 24 de noviembre de 1861, 77 años después en 1938 se construyó el templo de la calle 24 que fue declarado Bien de Conservación Arquitectónica. ${ }^{136}$ En Ibagué, la Iglesia fue organizada el 26 de mayo de 1940, en 1950 se construyó su templo, ${ }^{137}$ en 1955 se construyó el de Bucaramanga. ${ }^{138}$ Ambos templos fueron modernos, espaciosos y mejor equipados en el país para la época. $Y$ así se fueron construyendo los templos en cada municipio donde se establecía una iglesia.

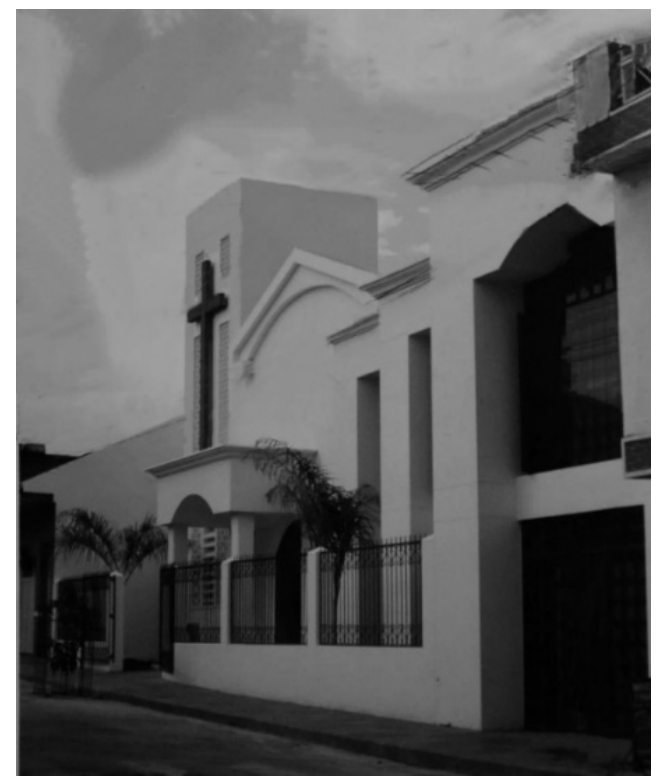

Foto. Iglesia Presbiteriana de Girardot, templo inaugurado en junio de 1958 como monumento conmemorativo del centenario de la Iglesia Presbiteriana de Colombia. Ubicada en la Calle 20 N. ${ }^{\circ} 10-66$ de Girardot.

Fuente: Archivo fotográfico personal Luis Eduardo Ramírez, Girardot, 1999.

oficiales - Consistorio y Diáconos - y un pastor; Consejo Directivo y Administrativo del Sínodo 20092013, Constitución Nacional de la Iglesia Presbiteriana en Colombia, Sínodo Reformado, Capítulo 3 (Santa Marta, Colombia: IPCSR, 2011); La Constitución de la Iglesia Presbiteriana (E.U.A), Libro de Orden, Versión en español, la Oficina de la Asamblea General, Louisville, 2004, G-7.0000; Ordóñez, 80; Rodríguez, Hacia una historia ..., 128-133, 143.

136 Eduardo G. Seel, «El nuevo templo presbiteriano de Bogotá», El Evangelista Colombiano, Serie XXIII, No. 318 (Bucaramanga: enero de 1939): 1; Eduardo G. Seel, «La dedicación del nuevo templo de Bogotá», El Evangelista Colombiano, Serie XXIII, No. 321 (Bucaramanga: abril de 1939): 1; Rodríguez, Hacia una historia..., 236; Ordóñez, Historia del cristianismo..., 55 y 70; Edgardo Bassi Burgos, «Primera Iglesia Presbiteriana de Bogotá, Príncipe de Paz. Reseña histórica y arquitectónica», en Suárez, Primera Iglesia Presbiteriana ..., 151-158; Bucana, La Iglesia evangélica ..., 63-65.

137 Roberto Lazear, «De Ibagué», El Evangelista Colombiano, Serie XXXI, No. 368 (Bucaramanga: marzo de 1943): 1; Ordóñez, Historia del cristianismo..., 144; Bucana, La Iglesia evangélica ..., 70-71.

138 Ordóñez, 128-130. Archivo Iglesia Presbiteriana de Bucaramanga -AIPB_, documentos varios. 
Uno de los templos que reflejó la teología reformada fue el de la Ciudad de Girardot, construido en celebración del centenario de la Iglesia Presbiteriana en Colombia. La Iglesia Presbiteriana de Girardot fue organizada el 29 de julio de 1945, el templo y los primeros edificios del colegio fueron inaugurados en junio de $1958,{ }^{139}$ porque al lado del templo se construía un colegio, para el presbiteriano culto y educación eran las dos caras de la misma moneda. ${ }^{140}$

Las demás Iglesias Presbiterianas mantuvieron los ornamentos litúrgicos; por el contrario, la Iglesia de Girardot decidió, de manera consciente, como una forma de diferenciarse de la Iglesia Católica, ser minimalista en su expresión ornamental. Su altar o presbiterio fue diseñado acorde a su teología, en el centro del altar o presbiterio estaba ubicado el púlpito, delante y en un nivel más bajo se encontraba ubicada la mesa de la Cena del Señor, al lado derecho estaba el órgano, al lado izquierdo el coro y al fondo en la pared estaba la cruz vacía, simbolizando la resurrección de Cristo. Era una forma visual de representar la esencia del mensaje presbiteriano: centralidad de las Escrituras, culto como celebración y encuentro con el Cristo resucitado, y eliminación de cualquier diferenciación entre sacerdote y feligrés, enfatizando el sacerdocio universal de todos los creyentes.

Gráfica 1. Planos contrastados Iglesia Presbiteriana de Girardot e Iglesia Católica $^{141}$
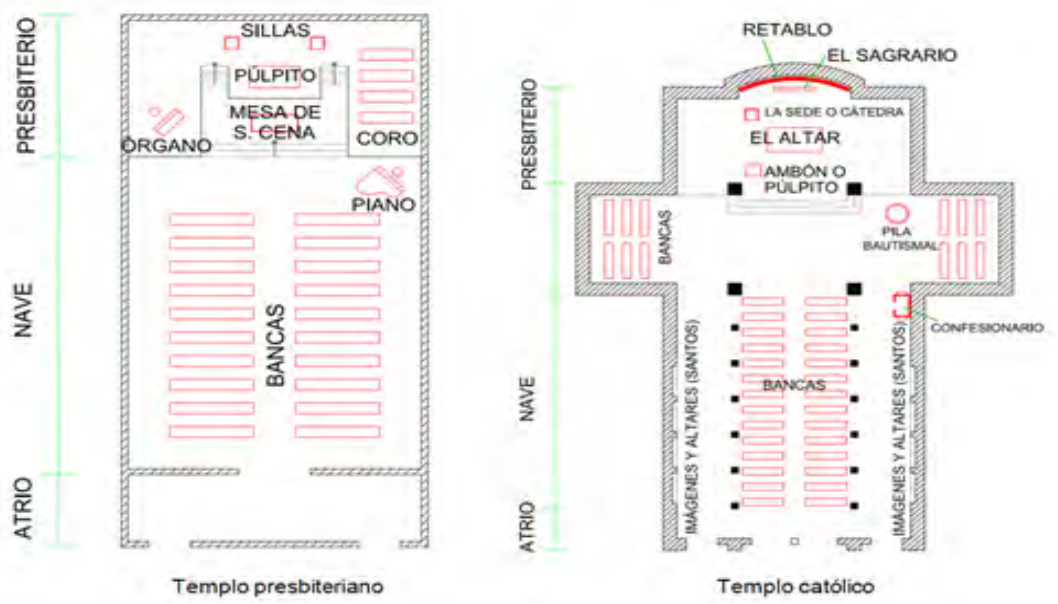

139 Carmen de Gahona, «Semblanza Iglesia Presbiteriana de Girardot. Monumento del primer centenario de la obra en Colombia», en Suárez, Primera Iglesia Presbiteriana, 59-60; Archivo Iglesia Presbiteriana de Girardot, -AIPG-, Libro No. 1 de Actas (Girardot, Colombia: 1945); Bazcko, Los imaginarios sociales, 41-45. 140 Bastian, Protestantismo y modernidad..., 129.

141 Plano elaborado por el arquitecto Juan Carlos Vega Higuera, 13 de febrero de 2020. 
Para los presbiterianos su teología nacida de la reflexión bíblica se expresó en el culto, la liturgia y sus templos que reflejó un sentido propio, el sentido presbiteriano: ${ }^{142}$

\begin{abstract}
Como todo grupo social, las iglesias presbiterianas han desarrollado rasgos característicos que las identifican, que son transmitidos de generación en generación y se van enriqueciendo en la medida que profundizan su experiencia de fe. Es en este madurar de su identidad como grupo que éste comienza a promover cambios en su contexto. [...] para dar respuesta a los desafíos que plantea cada época en la que ha de estar presente. Aunque en la [Iglesia Presbiteriana de Colombia] IPC toda comunidad local tiene sus propias características, todas ellas conservan una identidad presbiteriana que las hace diferentes a otras confesiones religiosas. $^{143}$
\end{abstract}

\title{
Consideraciones finales
}

Esta mirada histórica al desarrollo del culto, liturgia y templos en la Iglesia Presbiteriana en Colombia, desde su establecimiento en el país a mediados del siglo XIX y su consolidación en el siglo XX, en un contexto de confrontación y diferenciación, primero frente a la Iglesia Católica y luego frente a la influencia de los movimientos teológicos al interior del protestantismo, permite ver cómo, a través de un proceso consciente de reflexión teológica, intentó ser relevante a su contexto expresando lo autóctono sin renunciar a su herencia teológica e histórica. ${ }^{144}$

El periodo de los gobiernos liberales de mediados del siglo XIX fue propicio para el establecimiento de la Iglesia Presbiteriana, pero en confrontación directa con la Iglesia Católica Tridentina antiprotestante. El culto y la liturgia de los presbiterianos en estos primeros años adoptó el modelo estadounidense y afirmó las doctrinas de la Reforma Protestante del siglo XVI. Para los primeros convertidos esta nueva fe implicó un cambio radical de creencias y una ruptura definitiva con la Iglesia Católica, lo que evidenció que en el país había irrumpido una nueva expresión del cristianismo. En las primeras décadas del siglo $\mathrm{XX}$, anteriores a las dos guerras mundiales, los presbiterianos importaron un culto optimista influenciado por los grandes avivamientos de los dos siglos anteriores en las colonias norteamericanas. Los Congresos Misioneros de Edimburgo (1910) y Panamá (1916) definieron las líneas y agenda del protestantismo latinoamericano, que se desarrollaron desde una corriente ecuménica y otra 
evangélica. A mediados del siglo, en el periodo de la violencia política y la persecución religiosa (1948-1958), la iglesia cantó una himnología Cristo céntrica y de esperanza en la vida eterna. Por otro lado, el Concilio Vaticano II renovó la Iglesia Católica y la forma de relacionarse con las Iglesias Protestantes; la II Conferencia General del Episcopado Latinoamericano (1968), con su énfasis en la agenda social y su opción por los pobres, impactó el culto y la praxis tanto de católicos como de protestantes. Más adelante, en la década de los 80 , las iglesias del país experimentaron, en su culto y teología, el impactó del movimiento pentecostal.

Como se puede evidenciar, la liturgia desarrollada por los presbiterianos recibió la influencia de factores tanto exógenos como endógenos de índole social, cultural, político y religioso. Resaltar este hecho histórico del presbiterianismo en Colombia brinda la posibilidad de desmarcar el quehacer protestante de la acusación que le fue hecha de ser una religión impuesta con el fin de propagar la ideología política estadounidense en detrimento de identidad nacional. ${ }^{145}$ Siguiendo el pensamiento de Evans-Pritchard, las representaciones y los modos de pensar son parte de sus estructuras sociales, y en la medida en que estas varían, varían también las representaciones y el pensamiento del individuo. ${ }^{146}$

La arquitectura de los templos presbiterianos respondió a los postulados de la teología reformada de la centralidad de la Biblia, el sacerdocio de todos los creyentes y el encuentro con el Cristo resucitado. El canto y la arquitectura de los presbiterianos reflejaron los cambios en sus creencias, que a su vez se manifestaron en sus representaciones, imaginarios y prácticas que se materializaron en sus instituciones y discursos, tal como lo permite analizar la historia cultural. Este análisis interno del presbiterianismo colombiano, a través de una mirada histórica de su culto, liturgia y templos, pretende hacer un pequeño aporte, debido a que es un tema que ha sido poco explorado y más aún se carece de estudios académicos que se enfoquen en las iglesias evangélicas en Colombia.

\section{Archivos}

Archivo Asociación Presbiterio del Sur-AAPS-.

Archivo Iglesia Evangélica Presbiteriana de Medellín -AIEPM-.

Archivo Iglesia Presbiteriana Central de Bogotá -AIPCB-.

Archivo Iglesia Presbiteriana de Bucaramanga-AIPB-.

145 Carlos Mondragón, Leudar la masa. El pensamiento social de los protestantes en América Latina: 19201950 (Buenos Aires, Argentina: Kairós, 2005), 9-11; Erwin Rodríguez, Un evangelio según la clase dominante (México, D.F.: UNAM, 1982); Arturo Piedra, Evangelización protestante en América Latina. Análisis de las razones que justificaron y promovieron la expansión protestante, 180-1960 (Quito, Ecuador: CLAI-UBL, 2000); Salinas, Teología con alma ..., 13.

146 E.E. Evans-Pritchard, Las teorías de la religión primitiva, $4^{\mathrm{a}}$ ed. (Madrid, España: Siglo XXI Editores, 1984), 131; Pierre Bourdieu, Razones Práctica sobre la teoría de la acción, Trad. de Thomas Kauf (Barcelona, España: Anagrama, 1997), 20. 
Archivo Iglesia Presbiteriana de Colombia-AIPC-.

Archivo Iglesia Presbiteriana de Girardot, -AIPG-.

\section{Entrevistas}

Aguirre, Uriel, entrevistado por Luis Eduardo Ramírez, Medellín, diciembre 23 de 2016. Anciano Gobernante Iglesia Presbiteriana de Ibagué.

Aranzalez, Dayro e Isaí Pérez, entrevistados por Luis Eduardo Ramírez, Medellín, junio15 de 2018.

Argel, Roberto, entrevistado por Luis Eduardo Ramírez, Medellín, septiembre 18 de 2015. Ministro Iglesia Presbiteriana en Colombia.

Barraza, Helis, entrevistado por Luis Eduardo Ramírez, Medellín, junio 25 de 2016. Anciano Gobernante Iglesia Presbiteriana de Barranquilla.

Vanegas, Sara, entrevistada por Luis Eduardo Ramírez, Medellín: septiembre 17 de 2015 y diciembre 27 de 2016. Ministra Iglesia Presbiteriana en Colombia.

Voelkel, Javier, entrevistado por Luis Eduardo Ramírez, Medellín, julio 13 de 2015 y agosto 16 de 2017. Misionero presbiteriano.

\section{Libros}

Allan, Alexander M. Recuerdos 1910-1945. Medellín, Colombia: Unión, s. f. Calvino, Juan, Institución de la Religión Cristiana (Inst.), 3. ${ }^{\mathrm{a}}$ ed. Volumen I y II, Rijswijk, Países Bajos: Felire, 1968.

Constitución de la Iglesia Presbiteriana de Colombia. Presentación Rev. Guidoberto Mahecha. Bogotá, Colombia: Buena Semilla, 1987.

Constitución Nacional de la Iglesia Presbiteriana en Colombia, Sínodo Reformado. Santa Marta, Colombia: IPCSR, 2011.

Constitución de la Iglesia Presbiteriana (E.U.A). Libro de Orden. Versión en español. Louisville, E.U.A.: Oficina de la Asamblea General, 2004.

El Nuevo Testamento de nuestro señor y salvador Jesucristo, Versión Moderna, [Trad. H.B. Pratt]. Nueva York, EE. UU.: Sociedad Bíblica Americana, 1894. http:/historiayverdad.org/biblias-textos-biblicos/El-Nuevo-Testamento-de-nuestro-Senior-y-Salvador-Jesu-Cristo-Version-Moderna-1894.pdf.

Goff, James E. The Persecution of Protestant Christians in Colombia, 19481958. Sondeos, n. ${ }^{\circ}$ 23. Cuernavaca, México: CIDOC, 1968.

Hendry, Georges. La Confesión de Westminster para el día de hoy: una interpretación actual. Trad. de Jorge Lara-Braud. Bogotá, Colombia: CEPAL, 1966.

Pratt, H. B. La Biblia y sus opositores: escrito dedicado a los romanistas adversarios de la Biblia y al señor José Manuel Groot en particular por $H$. B. Pratt ministro protestante en el Socorro. Bogotá, Colombia: Imprenta Gaitán, 1875. 


\section{Informes anuales de la misión}

The Twenty-Ninth Annual Report of the Board of Foreign Missions of the Presbyterian Church of the United States of America. New York: Presbyterian Church the USA, 1866.

The Fifty-First Annual Report of the Board of Foreign Missions of the Presbyterian Church of the United States of America. New York: Presbyterian Church the USA, 1888.

The Fifty-Ninth Annual Report of the Board of Foreign Missions of the Presbyterian Church of the United States of America, New York, Presbyterian Church the USA.

\section{Revista El Evangelista Colombiano}

Eduardo G. Seel, «El nuevo templo presbiteriano de Bogotá», El Evangelista Colombiano, Serie XXIII, n. ${ }^{\circ} 318$ (Bucaramanga: enero de 1939): 1.

Eduardo G. Seel, «La dedicación del nuevo templo de Bogotá», El Evangelista Colombiano, Serie XXIII, n. 321 (Bucaramanga: abril de 1939): 1.

Roberto Lazear, «De Ibagué», El Evangelista Colombiano, Serie XXXI, n. ${ }^{\circ} 368$ (Bucaramanga: marzo de 1943): 1.

\section{Fuentes secundarias}

\section{Libros}

Álvarez, Carmelo E. y Pablo Legget, eds. Lectura teológica del tiempo latinoamericano: Ensayos en honor del Dr. Wilton M. Nelson, San José, Costa Rica: Seminario Bíblico Latinoamericano, 1979.

Appleby, Joyce, Lynn Hunt y Margaret Jacob. Telling the Truth about History. New York - London, USA-UK: W.W. Norton \& Company, 1994.

Arboleda Mora, Carlos y Fernando Alexander Sanmiguel Martínez, comps. El diálogo ecuménico y el pensamiento de Calvino en sus 500 años. Medellín, Colombia: Universidad Pontificia Bolivariana, 2015.

Arias, Ricardo. El episcopado colombiano: intransigencia y laicidad, 1850 2000. Bogotá, Colombia: Uniandes, 2003.

Barreda Toscano, Juan José y Edesio Sánchez Cetina, eds. Arte, liturgia y teología. Lima, Perú: Puma, 2013.

Bastian, Jean Pierre. Protestantismo y modernidad latinoamericana. Historia de unas minorías religiosas activas en América Latina. México, D.F.: FCE, 1994.

Bazcko, Bronislaw. Los imaginarios sociales. Buenos Aires, Argentina: Editorial Nueva Visión, 1991.

Berkhof, Louis. Teología Sistemática. Trad. de Felipe Delgado Cortés. Jenison, E.U.A.: TELL, 1988. 
Bethell, Leslie, ed. Historia de América Latina. Barcelona, España: Crítica, 1991.

Bidegain, Ana María, dir. Historia del cristianismo en Colombia. Corrientes y diversidad. Bogotá, Colombia: Taurus, 2004.

Bonino, José Míguez, Conflicto y unidad en la Iglesia, San José, Costa Rica: SEBILA, 1992.

Bonino, José Míguez, Juan Sepúlveda y Rigoberto Gálvez, Unidad y diversidad del protestantismo latinoamericano. El testimonio evangélico hacia el tercer milenio: Palabra, Espiritu y Misión, CLADE IV. Buenos Aires, Argentina: Ediciones KAIROS, 2002.

Bonino, José Míguez. Rostro del protestantismo latinoamericano. Buenos Aires - Grand Rapids, Argentina-USA: Nueva Creación, 1995.

Bourdieu, Pierre. Razones prácticas sobre la teoría de la acción. Trad. de Thomas Kauf. Barcelona, España: Anagrama, 1997.

Bucana, Juana de. La Iglesia Evangélica en Colombia: una historia. Bogotá, Colombia: WEC International, 1995.

Builes, Miguel Ángel. Cartas pastorales. Bogotá, Colombia: Empresa Nacional de Publicaciones, 1957.

Bushnell, David. El régimen de Santander en la Gran Colombia. Bogotá, Colombia: El Áncora, 1985.

Cabrera Becerra, Gabriel. Los poderes en la frontera. Misiones católicas y protestantes, y Estados en el Vaupés colombo-brasileño, 1923-1989. Medellín, Colombia: Universidad Nacional de Colombia, 2015.

Castillo Cárdenas, Gonzalo e Isay Pérez Benavides, La influencia religiosa en la conciencia social de Orlando Fals Borda, Barranquilla, Colombia: Corporación Universitaria Reformada, 2010.

Ceballos Gómez, Diana Luz, ed. Prácticas, territorios y representaciones en Colombia 1849-1960. Medellín, Colombia: Universidad Nacional de Colombia, 2009.

Ceballos Gómez, Diana Luz. Simbolismo y saber: el circuito de la cultura. Medellín, Colombia: Universidad Nacional de Colombia, 2018.

Chicangana-Bayona, Yobenj Aucardo y Liliana Cortés Garzón, eds. Peter Burke. Debates y perspectivas de la nueva historia cultural. Medellín: Universidad Nacional de Colombia, 2011.

Concilio Vaticano II, Constitución pastoral Gaudium et Spes, Sobre la Iglesia en el mundo moderno, 4. ${ }^{a}$ edición. Bogotá, Colombia: Ediciones Paulinas, 1970.

Concilio Vaticano II, Constitución Sacrosanctum Concilium, Sobre la sagrada Liturgia, 4. a edición. Bogotá, Colombia: Ediciones Paulinas, 1970.

Concilio Vaticano II, Declaración Dignitatis Humanae, Sobre la libertad religiosa, 4. edición. Bogotá, Colombia: Ediciones Paulinas, 1970. 
Concilio Vaticano II, Decreto Unitatis Redintegratio, Sobre el ecumenismo, 4. ${ }^{\mathrm{a}}$ edición. Bogotá, Colombia: Ediciones Paulinas, 1970.

Concordato entre la Santa Sede y la República de Colombia (1887), https://www. cec.org.co/sites/default/files/WEB_CEC/Documentos/Documentos-Historicos/1973\%20Concordato\%201887.pdf.

Documentos del Concilio de Trento, Sesión IV. Las Sagradas Escrituras. Celebrada el 8 de abril de 1546, http://www.conoze.com/doc.php?doc=5235.

Documentos del Concilio de Trento, Sesión VII. Los Sacramentos. Celebrada en el día 3 de marzo de 1517, http://www.conoze.com/doc.php?doc=5235.

Documentos del Concilio de Trento, Sesión XXII. El Sacrificio Eucarístico. 17 de setiembre de 1562, http://www.conoze.com/doc.php?doc=5235.

Documentos del Concilio de Trento. Sesión XIII. El Santísimo Sacramento de la Eucaristía. Celebrada en el día 3 de marzo de 1517, http://www.conoze. $\mathrm{com} /$ doc.php?doc $=5235$.

Donner, Theo, Una nueva forma de pensar. Borradores para una cosmovisión cristiana. Medellín, Colombia: SBC, 1993.

Donner, Theo. El Texto que interpreta al lector: una exposición de la Biblia. Medellín, Colombia: FUSBC, 2009.

Donner, Theo. Posmodernidad y fe: una cosmovisión cristiana para un mundo fragmentado. Barcelona, España: CLIE, 2012.

Donner, Theo. Una introducción a la historia y teología de la Reforma. Medellín, Colombia: Seminario Bíblico de Colombia, 1987.

Duque, José, ed., Por una sociedad donde quepan todos. San José, Costa Rica: DEI, 1996.

Durkheim, Emile. Las formas elementales de la vida religiosa. Trad. de Ramón Ramos. Madrid, España: Akal, 1982.

Eliade, Mircea. Imágenes y símbolos. Ensayos sobre el simbolismo mágico-religioso, Versión española de Carmen Castro, $3^{\mathrm{a}}$ ed. Madrid, España: Taurus, 1979.

Eliade, Mircea. Lo sagrado y lo profano. Trad. de Luis Gil. 4. ${ }^{a}$ ed. Barcelona, España: Guadarrama/Punto Omega, 1981.

Elías, Norbert. La sociedad de los individuos. Edición Michael Schöter. Trad. de José Antonio Alemany. Barcelona, España: Península, 1990.

Escobar, Samuel, La fe evangélica y las teologías de la liberación. El Paso, EE. UU.: Casa Bautista de Publicaciones, 1987.

Evans-Pritchard, E.E. Las teorías de la religión primitiva, 4. ${ }^{\mathrm{a}}$ ed. Madrid, España: Siglo XXI Editores, 1984.

González B., Valentín. Patricio Symes. Vida y obra de un pionero. Bogotá, Colombia: Iglesia Cruzada Cristiana, 2000.

González, Justo L. Historia del cristianismo: desde la era de la reforma hasta la era inconclusa, Tomo 2. Miami, Florida: UNILIT, 1994. 
González Santos, Andrés Eduardo, comp. Diversidad y dinámicas del cristianismo en América Latina, Bogotá, Colombia: Bonaventuriana, 2007.

Groot, José Manuel. Historia eclesiástica y civil de la Nueva Granada, Tomo IV. Bogotá, Colombia: Biblioteca de Autores Colombianos, 1953.

Guevara, Ignacio. Paria solitario: de niño de la calle a apóstol de Jesús. Bogotá, Colombia: La Buena Semilla, 2006.

Hubert, Henri, Breve estudio de la representación del tiempo en la religión y en la magia, Trad. Sonia Muñoz. Cali, Colombia: Archivos del Índice, 2006.

II Conferencia General del Episcopado Latinoamericano, Medellín. Conclusiones, la Iglesia en la actual transformación de América Latina a la luz del Concilio. Medellín, Colombia: CELAM, 1968.

Jaramillo Uribe, Jaime. Historia de la pedagogía como historia de la cultura. 2. ${ }^{a}$ ed. Bogotá, Colombia: Centro de Investigación y Educación Cooperativas - CIEC, 1978.

Kuyper, Abraham. Lectures on Calvinism. Grand Rapids, USA: Eerdmans, 1976.

Lewis, Gordon R. and Bruce A. Demarest, Integrative Theology. Spirit-Given Life: Good's People Present and Future, Vol. 3. Grand Rapids, USA: Zondervan, 1994.

López Michelsen, Alfonso. La estirpe calvinista de nuestras instituciones politicas. Bogotá, Colombia: Tercer Mundo, 1966.

Mackay, Juan A. El sentido presbiteriano de la vida: lo que significa vivir y adorar como presbiteriano. Trad. de Abel Clemente. Englewood, USA: Prentice Hall, s. f.

Mackay, Juan A., Las iglesias latinoamericanas y el movimiento ecuménico. New York, USA: CCAL, 1963.

Molina, Gerardo. Las ideas liberales en Colombia 1849-1959, 2ª ed. Bogotá, Colombia: Tercer Mundo Editores, 1971.

Mondragón, Carlos. Leudar la masa. El pensamiento social de los protestantes en América Latina: 1920-1950. Buenos Aires, Argentina: Kairós, 2005.

Nelson, Wilton M. Diccionario de la historia de la Iglesia. Miami, Florida: Caribe (1989): 542-543.

Nisbet, Robert. Historia de la idea de progreso. Trad. de Enrique Hegewicz. 2. ed. Barcelona, España: Gedisa, 1991.

Núñez, Emilio A., Teología de la liberación. Una perspectiva evangélica, San José, Costa Rica: Caribe, 1986.

Ordóñez, Francisco. Historia del cristianismo evangélico en Colombia. Bogotá, Colombia: CLC, 1956.

Ortega y Gasset, José. Historia como sistema. Madrid, España: ESPASA-CALPE, 1971. 
Ortiz Hurtado, Jaime. ¿Quiénes son los evangélicos? Creencias, posiciones y compromisos de los cristianos o evangélicos de la actualidad. Santafé de Bogotá, Colombia: Horizonte Impresores, 1995.

Ospina, Eduardo. Las sectas protestantes en Colombia: breve reseña histórica. Bogotá, Colombia: Imprenta Nacional, 1953.

Piedra, Arturo. Evangelización protestante en América Latina. Análisis de las razones que justificaron y promovieron la expansión protestante, 1801960. Quito, Ecuador: CLAI-UBL, 2000.

Quintero Aleans, Jesús David. Heretical Protestant Millionaires are pouring their Money into Colombia. El trato a las minorias religiosas, 1948-1953, Trabajo para optar al título de historiador. Bogotá, Colombia: Pontificia Universidad Javeriana, 2012.

Ramírez, Luis Eduardo. Aportes del principio reformado de la Sola Scriptura para la interpretación y enseñanza de la Biblia. Tesis de Maestría en Teología. Medellín, Colombia: SBC, 2001.

República de Colombia, Constitución de la República de Colombia. Bogotá, Colombia: Imprenta de Vapor de Zalamea HS., 1886.

República de Colombia. Constitución Política de los Estados Unidos de Colombia. Bogotá, Colombia: Imprenta i Estereotipia de Medardo Rívas, 1871.

Roberts, Dayton W. Los auténticos revolucionarios: la historia de evangelismo a fondo en América Latina. Trad. de José María Blanch. San José, Costa Rica: Caribe, 1969.

Rodríguez Baquero, Luis Enrique, Ana Luz Rodríguez, Jaime Humberto Borja, Diana Luz Ceballos, Carlos Uribe, Amparo Murillo y Ricardo Arias. Historia de Colombia. Todo lo que hay que saber. Bogotá, Colombia: Aguilar, Altea, Taurus, Alfaguara, 2011.

Rodríguez Sanín, Javier Augusto, Hacia una historia del protestantismo en Colombia. Medellín, Colombia: UPB y Corporación Honorable Presbiterio Central de la Iglesia Presbiteriana de Colombia, 2019.

Rodríguez, Erwin. Un evangelio según la clase dominante. México: UNAM, 1982.

Salinas, Daniel. Teología con alma latina: el pensamiento evangélico en el siglo $X X$. Lima, Perú: Puma, 2018.

Savage, Robert C., comp. Himnos de fe y alabanza. Cúcuta, Colombia: El Sembrador, 1966.

Schutmaat, Alvin. Culto Cristiano. San José, Costa Rica: SEBILA, 1985.

Seminario Bíblico Latinoamericano, comp. Celebremos juntos. San José, Costa Rica: SEBILA, 1989.

Shillingsburg, F. W. La llama que nunca se apaga. Breve historia de la Unión Misionera Evangélica durante sus setenta y cinco años de mantener en alto la llama, 1908-1983. Cali, Colombia: Aurora, 1983. 
Sproul, R. C. Escogido por Dios. Trad. de Demetrio Cánovas Moreno. Miami, Florida: Unilit, 1993.

Suárez, Germán Ezequiel, dir. Primera Iglesia Presbiteriana de Bogotá, Príncipe de Paz 150 años. Bogotá, Colombia: Buena semilla, 2006.

Tejeiro Sarmiento, Clemencia, ed., El pentecostalismo en Colombia. Prácticas religiosas, liderazgo y participación política. Bogotá, Colombia: Universidad Nacional de Colombia - CES, 2010.

Tirado Mejía, Álvaro. El Estado y la política en el siglo XIX, 4. ${ }^{\mathrm{a}}$ ed. Bogotá, Colombia: El Áncora Editores, 2001.

Tratado de amistad, comercio y navegación entre Colombia e Inglaterra, Tratado de la República de la Nueva Granada e Inglaterra. Bogotá, Colombia, 18 de abril de 1825.

Tratado general de paz, amistad, navegación y comercio entre la República de la Nueva Granada y los Estados Unidos de América, Tratado Mallarino-Bidlack. Bogotá, Colombia, 12 de diciembre de 1846.

Troeltsch, E. El protestantismo y el mundo moderno. Trad. de Eugenio Ímaz. México - Buenos Aires, México, Argentina: FCE, 1951.

Troeltsch, Ernst. The Social Teaching of the Christian Churches, Vol. 1, Trad. Olive Wyon. Londres, UK: George Allen and Unwin Ltd., 1949.

Weber, Max. La ética protestante y el espiritu del capitalismo. Trad. de Luis Legaz Lacambra. Barcelona, España: Península, 1999.

Wood, Robert D. In These Mortal Hands. The Story of the Oriental Missionary Society. The First 50 Years. Greenwood, USA: OMS International, 1983.

Zambrano, Carlos Vladimir, ed. Confesionalidad y politica. Confrontaciones multiculturales por el monopolio religioso. 2. ${ }^{\mathrm{a}}$ ed. Bogotá, Colombia: Universidad Nacional de Colombia, 2003.

\section{Capítulo de libros}

Anderson Carlson, Timoteo. «Reflexiones sobre la alabanza y la adoración a través de la historia». En: Primera Iglesia Presbiteriana de Bogotá, Príncipe de Paz 150 años, dir. German Ezequiel Suárez, 137-14. Bogotá, Colombia: Buena Semilla, 2006.

Arboleda Mora, Carlos. «El protestantismo en Colombia 1810-1920». En: El diálogo ecuménico y el pensamiento de Calvino en sus 500 años, comp. Carlos Arboleda Mora y Fernando Alexander Sanmiguel Martínez, 25-59. Medellín, Colombia: Universidad Pontificia Bolivariana, 2015.

Bassi Burgos, Edgardo. «Primera Iglesia Presbiteriana de Bogotá, Príncipe de Paz. Reseña histórica y arquitectónica». En: Primera Iglesia Presbiteriana de Bogotá, Príncipe de Paz 150 años, dir. German Ezequiel Suárez, 151-158. Bogotá, Colombia: Buena Semilla, 2006. 
Beltrán, William. «El evangelicalismo y el movimiento pentecostal en Colombia en el siglo XX». En: Historia del cristianismo en Colombia: corrientes y diversidad, Ana María Bidegain, 451-480. Bogotá, Colombia: Taurus, 2004.

Beltrán Cely, William Mauricio «La expansión pentecostal en Colombia». En: El pentecostalismo en Colombia. Prácticas religiosas, liderazgo y participación politica, ed. Clemencia Tejeiro Sarmiento, 73-96. Bogotá, Colombia: Universidad Nacional de Colombia - CES, 2010.

Bonino, José Míguez. «El rostro liberal del protestantismo». En: Unidad y diversidad del protestantismo latinoamericano. El testimonio evangélico hacia el tercer milenio: Palabra, espiritu y misión, CLADE IV, José Míguez Bonino, Juan Sepúlveda y Rigoberto Gálvez, 11-33. Buenos Aires, Argentina: Ediciones KAIROS, 2002.

Builes, Miguel Ángel. «La corrupción avanza. Febrero 24 de 1953». En: Cartas pastorales, Miguel Ángel Builes, 233-237. Bogotá, Colombia: Empresa Nacional de Publicaciones, 1957.

Burke, Peter. «Una historia cultural y social de los desechos». En: Peter Burke. Debates y perspectivas de la nueva historia cultural, eds. Yobenj Aucardo Chicangana-Bayona y Liliana Cortés Garzón, 73-88. Medellín, Colombia: Universidad Nacional de Colombia, 2011.

Ceballos, Diana Luz. «Desde la formación de la República hasta el Radicalismo liberal (1830-1886)» . En: Historia de Colombia. Todo lo que hay que saber, Luis Enrique Rodríguez, Luis Enrique, Ana Luz Rodríguez, Jaime Humberto Borja, Diana Luz Ceballos, Carlos Uribe, Amparo Murillo y Ricardo Arias, 165-216. Bogotá, Colombia: Aguilar, Altea, Taurus, Alfaguara, 2011.

Chiquete, Daniel. «Arquitectura cristiana: características y significados». En: Arte, liturgia y teología, eds. Juan José Barreda y Edesio Sánchez, 98108. Lima: Puma, 2013.

Demera Vargas, Juan Diego y Rodríguez Leuro, Aida Patricia. «Minorías religiosas y persecución protestante. Colombia 1948-1957». En: Confesionalidad y política. confrontaciones multiculturales por el monopolio religioso, ed. Carlos Vladimir Zambrano, (2 ed.), 295-312, Bogotá, Colombia: Universidad Nacional de Colombia, 2003.

Durkheim, Emile. «El porvenir de la religión (1914)». En: Breve estudio de la representación del tiempo en la religión y en la magia, Henri Hubert, (Sonia Muñoz, Trad.), 79-93. Cali, Colombia: Archivos del Índice, 2006.

Gahona, Carmen de. «Semblanza Iglesia Presbiteriana de Girardot. Monumento del primer centenario de la obra en Colombia». En: Primera Iglesia Presbiteriana de Bogotá, Príncipe de Paz 150 años, dir. German Ezequiel Suárez, 59-60. Bogotá, Colombia: Buena Semilla, 2006. 
Munévar, Jorge. «La libertad religiosa en Colombia: orígenes y consecuencias». En: Historia del cristianismo en Colombia. Corrientes y diversidad, dir. Ana María Bidegain, 247-256. Bogotá, Colombia: Taurus, 2004.

Roa, Jairo. «El desarrollo desde la perspectiva de la teología en América Latina».

En: Diversidad y dinámicas del cristianismo en América Latina, comp. Andrés Eduardo González, 69-127. Bogotá, Colombia; Bonaventuriana, 2007.

Rodríguez, Javier Augusto. «Primeros intentos de establecimiento del protestantismo en Colombia». En: Historia del cristianismo en Colombia. Corrientes y diversidad, dir. Ana María Bidegain, 287-320. Bogotá, Colombia: Taurus, 2004.

Toon, Peter. «Controversia de la iconoclastia». En: Diccionario de la Historia de la Iglesia, Wilton M. Nelson, 542-543. Miami, Florida: Caribe, 1989.

\section{Revistas}

Aguilera, Mario. «La secesión de Panamá: noviembre 3 de 1903». Banrepcultural. https://www.banrepcultural.org/biblioteca-virtual/credencial-historia/ numero-117/la-secesion-de-panama-noviembre-3-de-1903.

Beltrán Cely William Mauricio. «Del porque los pentecostalismos no son protestantismos». Creer y poder hoy, memorias de la cátedra Manuel Ancízar. Bogotá: Universidad Nacional de Colombia, (2007): 469-485. https://repositorio.unal.edu.co/handle/unal/10737.

Beltrán Cely, William Mauricio. «Pluralización religiosa y cambio social en Colombia». Theologica Xaveriana, n. ${ }^{\circ} 175$ (enero-junio, 2013): 57-85. https://repositorio.unal.edu.co/handle/unal/75037.

Bourdieu, Pierre. «Génesis y estructura del campo religioso». Relaciones, vol. 27, n. 108 (2006): 29-83. https://www.colmich.edu.mx/relaciones25/files/revistas/108/pdf/PierreBourdieu.pdf.

El Evangelista Colombiano, 1939-1943.

Escobar, Samuel. «La fundación de la Fraternidad Teológica Latinoamericana: breve ensayo histórico». Boletín Teológico, año 27, n. ${ }^{\circ}$ 59-60 (julio-diciembre, 1995): 7-25.

Escobar, Samuel, «Los movimientos de cooperación evangélica en América Latina». Misión, vol. 1, n. ${ }^{\circ} 1$ (marzo-junio 1982): 103-114.

Escobar Samuel, «¿Qué significa ser evangélico hoy?». Misión, vol. 1, n. ${ }^{\circ} 1$ (marzo-junio 1982): 15-39.

Guhrt, Joachim. «La confesión de fe y su formación en la actualidad». Diálogo Ecuménico, Tomo XX, n. 68 (1985): 363-380.

Míguez Bonino, José. «Las iglesias protestantes y evangélicas en América Latina y el Caribe: un ensayo interpretativo». Cuadernos de Teología, vol. 14, n. ${ }^{\circ} 2$ (1995): 29-38. 
Moorhead, James H. «The erosion of postmillennialism in American religious thought, 1865-1925». Church History, vol. 53, n. ${ }^{o} 1$ (1984): 6177. https:// doi.org/10.2307/3165956.

Petersen, Adam. «The Premillennial Menace: Shailer Mathews Theological-Political Battle Against Premillennialism During the First World War». Journal of Church \& State, vol. 60, n. ${ }^{\circ} 2$ (2018): 271-298, https://doi. org/10.1093/jcs/csx051.

Ramírez Suárez, Luis Eduardo. «Una historia de la Iglesia Presbiteriana en Colombia, 1993-2013». Ventana Teológica, año 4, $5^{\text {a }}$ ed. (4 de diciembre de 2013): 21-26. http://www.unisbc.edu.co/files/VT05-Art03-Ramrez2013. pdf.

Salinas, Daniel. «Historical Perspective on Evangelism and Discipleship in Latin America». Latin America Evangelist, vol. 86, n. ${ }^{\circ} 1$ (marzo-junio, 2006): 6.

Sardiñas Iglesias, Loida. «Iglesias, identidad y plurirreligiosidad: una mirada al protestantismo histórico». Albertus Magnus, vol. 7, n. ${ }^{\circ} 2$ (2016): 259-292. https://doi.org/10.15332/s2011-9771.2016.0002.04.

Shaull, Richard. «La Iglesia, crisis y nuevas perspectivas». Vida y Pensamiento, vol. 15, n. ${ }^{\circ} 2$ (1995): 8-48.

Uribe Botero, Ángela. «¿Puede el uso de metáforas ser peligroso? Sobre las pastorales del monseñor Miguel Ángel Builes». Revista de Estudios Sociales, n..$^{\circ} 34$ (diciembre, 2009): 113-122.

Walvoord, John F. «Postmillennialism». Bibliotheca sacra, vol. 106, $\mathrm{n}^{\circ} .422$ (1949): 149-168.

\section{Otras fuentes}

Ebenezer Honduras. «Alguien está aquí». https://genius.com/ Ebenezer-honduras-alguien-esta-aqui-lyrics.

Iglesia Presbiteriana de Girardot, Archivo fotográfico personal de Luis Eduardo Ramírez, Girardot, 1999.

PCUSA. «Who Are We Presbyterians». Video de Youtube, 17:32. Publicado el 8 julio de 2016. https://www.youtube.com/watch?v=1ZJcWNUmvfc.

Vega Higuera, Juan Carlos. Planos contrastados Iglesia Presbiteriana de Girardot e Iglesia Católica. Medellín: 13 de febrero de 2020. 